\title{
The N0 Neck in Oral Squamous Cell Carcinoma A Comprehensive Review and Update on Diagnosis and Management
}

\author{
Neel Patel ${ }^{1 *}$, Waleed Zaid ${ }^{2}$ and Beomjune $\mathrm{Kim}^{3}$ \\ ${ }^{1}$ Department of Surgery, University of Miami, US \\ ${ }^{2}$ Oral and Maxillofacial Surgery, Louisiana State University, US \\ ${ }^{3}$ Director of Head and Neck, Cancer Treatment Centers of America, US
}

Submission: March 23, 2020; Published: April 09, 2020

*Corresponding author: Neel Patel, Department of Surgery, Division of Oral and Maxillofacial/Head and Neck Surgery, University of Miami, US

\begin{abstract}
Oral cavity cancer represents one of the most devastating diseases worldwide, as the morbidity and mortality associated with it can be quite significant. Spread to cervical lymph nodes represents a major contributor to patient prognosis, however, despite many technological advances, accurate and consistent identification of involvement of the neck in early stage oral squamous cell carcinoma remains a major challenge. With increasingly sensitive and specific imaging modalities, cytological analysis, as well as sentinel node biopsy, identification of regional cervical metastasis continuously improves. The spread of this disease to regional lymph nodes of the neck often results in dramatic changes in treatment and prognosis, and thus management of the neck in early oral cancer is of paramount importance. A consensus on the ideal treatment modality for the clinically node-negative neck still eludes us, with elective neck dissection at the time of primary treatment being the current gold standard, with radiation and chemotherapy having adjunctive roles. The "wait and see" philosophy also has its advocates, as well as its critics. Advances in genetic analysis of tumours may represent the future in patient-specific intervention. This article represents a review of past, present, as well as future advances in the diagnosis and management of the N0 neck in oral cancer, highlighting the most recent research, techniques, and practices worldwide.
\end{abstract}

keywords: Oral cancer; N0 neck; Node negative neck; Oral squamous cell carcinoma; Neck dissection

\section{Introduction}

Cancer of the head and neck region is one of the most devastating diseases globally, accounting for an important portion of the cancer burden worldwide. The oral cavity is the most common site in the head and neck for the development of cancer, and consists predominantly of squamous cell carcinoma (SCC) [1]. It represents the $6^{\text {th }}$ most common cancer and the $8^{\text {th }}$ most common cancer-related mortality [2]. This is likely due to the widespread use of tobacco and alcohol around the world [3], which has been shown to have a synergistic effect on the development of oral cancer [4]. Other studies have shown that alcohol consumption is an independent risk factor for the development of oral cancer in a dose-dependent manner [5-7].

Oral cavity cancer is defined as a malignant lesion of one or more of the following: buccal mucosa, floor of mouth, oral tongue, alveolar gingiva, retromolar trigone, and hard palate. One of the most controversial and disputed aspects for the treatment of oral squamous cell carcinoma (OSCC) is in the early stages of the disease, when clinical and radiographic assessment of the extent of the disease process shows no clinical involvement of the neck (N0 neck). The importance of proper management of the neck in OSCC is evident; metastasis to the lymphatics of the neck accounts for the most important factor for survival and poor prognosis, as it demonstrates a 50\% decrease in 5-year survival [8-12].

Moreover, the rate of occult metastasis for OSCC in the literature ranges from $20 \%$ to $45 \%$, thus it is an important factor to consider in its treatment [13-18]. Of all the sites in the oral cavity, the oral tongue and the floor of the mouth demonstrate the highest propensity for regional lymphatic spread in the early stages, likely owing to the rich vascular and lymphatic supply of those anatomic regions [19]. Both depth of invasion as well as primary tumor size have been seen to have a significant effect on lymphatic metastasis in these tumours [20]. Different treatment 
strategies have been implemented over the decades, and of these, elective neck dissection at the time of the initial primary tumour resection has proven to be the most popular approach. However, neck dissection procedures do not come without a price; additional risk of infection, chyle leak from injury to the thoracic or lymphatic duct, arrhythmias from manipulation of the carotid bulb [21], as well as the well-described shoulder dysfunction from injury to the spinal accessory nerve [22-24] are some of the significant complications.

Radiation therapy, and occasionally chemotherapy have also been employed as either alternatives or adjuncts to surgical intervention. Many centers have practiced the "wait and see" philosophy, thus saving the patient elective treatment, however neck involvement that is discovered at a later stage carries with it a more extensive salvage surgery, and associated higher morbidity and mortality. Thus the question of how to treat the N0 neck in early oral SCC becomes a more difficult one to answer. Another aspect that must be looked at in today's world is cost benefit analysis as well as views from the patient's perspective when looking at workup, disease stratification modalities, and definitive therapy. Thus the goal of this article is to provide a comprehensive updated look at the current state of affairs for diagnosis and management of the N0 neck in SCC of the oral cavity.

\section{Diagnosis of the N0 Neck}

Knowing that the presence of neck lymph node metastasis decreases survival by about half as reported in the literature, the importance of proper diagnosis of the NO neck cannot be understated. Currently, clinical and radiographic examinations are the mainstay for clinical diagnosis. Unfortunately, the sensitivity, specificity, and negative predictive value (NPV) of these methods for determination of spread to the neck remain inadequate $[25,26]$. In regards to clinical examination by palpation, even in the hands of the most experienced head and neck surgeons, the sensitivity is reported to be only between $50-82 \%$ [27-33]. Thus, in addition to a thorough clinical examination, other modalities must be used to diagnose and accurately stage the disease.

\section{Advanced Imaging Techniques}

The combination of a thorough head and neck examination, along with radiographic imaging, has become the mainstay of diagnosis and staging of oral cancer. Imaging modalities have included computed tomography (CT), magnetic resonance imaging (MRI), positron emission tomography (PET), the combination of PET and CT technology, and ultrasound (US), the latter being more recently combined with cytologic evaluation by way of US-guided fine needle aspiration. Using very sensitive criteria will render a high sensitivity but a low specificity for the N0 neck, whereas more strict criteria will render a low sensitivity and a higher specificity [34]. CT and MRI are widely used to stage the neck. However with CT scans having only a sensitivity of 66 to
$85 \%$ [35] and MRI having a sensitivity of 64 to $93 \%$ [36,37], many patients may go on with undetected disease.

Several criteria for positive lymph node metastasis have been reported, but those reported by van den Brekel et al have gained widespread acceptance and are still used today: at least $10 \mathrm{~mm}$ in axial diameter, the presence of central lucency/necrosis, groups of 3 or more borderline nodes, and extracapsular spread (ECS) [38,39]. Unfortunately, these modalities are limited by the fact that the size of the involved lymph node(s) must ideally be at least $5 \mathrm{~mm}$ before they can be detected [40]. One of the limitations of imaging in determining neck involvement is the fact that the long axis of the node being evaluated is seldom in the exact plane or axis of the cut of the imaging modality, causing foreshortening and a potential false negative result [41]. Cellular metastatic disease may not even produce any gross changes in the node, and even grossly abnormal nodes may remain undetected in some examination, thus contributing to failure to detect disease [42].

It is estimated that approximately $25 \%$ of tumourpositive elective neck dissections of clinically NO necks contain micrometastasis smaller than $3 \mathrm{~mm}$, therefore virtually undetectable by today's imaging technologies [43]. The range for negative predictive value of staging CT scans is between 56 and $78 \%$ [44-47], indicating that in some instances almost half of patients diagnosed with an N0 neck ended up having occult neck metastasis on pathological evaluation. Furthermore, some metastatic nodes contain tumour cells that remain undetected even on histological slides prepared with conventional haematoxylin and eosin staining, and may only be detected by immunohistochemically and molecular analysis [48]. Immunohistochemically studies have found additional micrometastasis in 5-50\% (mean of 15.2\%) of patients who had no evidence of metastatic disease on routine imaging and pathological evaluation [49].

The use of molecular analysis in combination with imaging studies increases the rate of detection of micrometastasis [5053]. A recent meta-analysis examined the use of ultra-small superparamagnetic iron oxide (USPIO)-enhanced MRI to detect lymph node metastasis in various areas of the body, and showed that the diagnostic performance is higher than with conventional MRI, and that it is sensitive and specific for the detection of lymph node metastases [54]. Although the specificity of USPIO-MRI was better than that of MRI, its potential use in detection of metastasis still remains limited by technical problems such as motion artifact and problems with spatial resolution [55].

The introduction of 18F-fluorodeoxyglucose positron emission tomography (18FDG-PET) imaging to detect lymph node metastases gave rise to a marked improvement in sensitivity (75\% to $90 \%$ ) and specificity ( $94 \%$ to $99 \%$ ), with this high specificity decreasing the likelihood of false positives and overtreatment of patients [56-58]. The use of 18FDG-PET is thought to be a complementary rather than an alternative diagnostic tool because 
of its limitations in morphological resolution. Multiple studies have shown that the minimum criteria for detection of a positive node on PET was similar to MRI or CT alone, approximately $4-5 \mathrm{~mm}$, thus demonstrating an inability to detect metastatic disease in small diameter nodes [59-61].

The negative predictive value of 18FDG-PET has been shown to be in excess of $80 \%$ [62-64], which would imply that if a patient has a negative PET scan, one can be confident that the risk of nodal metastasis is $<20 \%$, and therefore elective treatment may not be necessary, if one follows the $20 \%$ treatment threshold that is generally accepted today. In a study by Krabbe et al, the prevalence of occult metastasis was $26 \%$ in the T2-T4 group, and the use of PET decreased the risk of occult metastasis to $13 \%$ in the same group, with PET having a NPV of $84 \%$. This could suggest that the T2-T4 group might be suitable for a watchful waiting policy in case of a negative PET scan. However due to the low prevalence of cervical metastases in this population, a relatively high number of true negative results are expected, which would result in a higher specificity and negative predictive value.

Because of this possible bias, it is not yet appropriate to conclude that a negative PET scan could be suitable for watchful waiting policy in the N0 neck [65]. Another potential drawback is in nodes demonstrating extensive necrosis, where uptake of marker would be inherently diminished, thus resulting in a falsely negative scan [66]. Moreover, neutrophils and macrophages during an ongoing inflammatory or granulomatous process demonstrate increased FDG accumulation and thus is a source of false-positive PET scans. Combination of the functional information provided by the PET scan (tumor viability with increased glycolysis as compared to normal tissues, with consequent increase in 18FDG uptake) along with the anatomical detail of the CT scan, was a significant advancement in diagnostic accuracy.

Jeong et al. [67] showed PET/CT was more accurate in detection of involved cervical nodes as compared to each modality alone, with sensitivity of $91.8 \%$ and specificity of $98.8 \%$. The use of contrast-enhancement in PET/CT aids in localization of the regions of increased 18FDG uptake, differentiating between lymph nodes and brown fat, thus increasing specificity, as well as localizing in areas of necrosis where uptake is less evident, increasing sensitivity [67]. Despite this, multiple studies have found much lower sensitivity and specificity data, with sensitivities ranging from $57 \%$ to $84.2 \%$, and specificities of 76.5 to $82 \%$ [68-70]. A more recent study by Schaefferkoetter and Carlson compared FDG with the use of 18-fluorothymidine (FLT) tracer in combination with PET scan in the evaluation of the neck. In their study, the use of FLT increased sensitivity from $43.2 \%$ to $75.7 \%$ in qualitative analysis of lymphatic tissue. However in terms of quantitative analysis, FDG still performed better when using the standard uptake value (SUV) scale [71].

Another diagnostic modality that has been used is the ultrasound-guided fine needle aspiration cytology, which was popularized in Europe in the late 1980s. The major advantage of combining ultrasound and cytology is that ultrasound is capable of detecting very small lymph nodes, whereas cytology will assure that the specificity remains in the range of $100 \%$, as false-positives are exceedingly rare [72]. For ultrasound studies, besides the size of the node, the following additional criteria have been used to distinguish between normal nodes and those suspicious of harbouring metastatic disease: absence of an echogenic hilus, presence of coagulation or cystic necrosis, abnormal vessels, eccentric cortical hypertrophy, and hypoechoic sonomorphology $[73,74]$.

Based on results from previous studies, lymph nodes with a minimal axial diameter larger than $4 \mathrm{~mm}$ in level II, and $3 \mathrm{~mm}$ in other levels of the neck should be selected for ultrasound-guided FNAC in order to obtain optimal sensitivity [75]. The sensitivity of this procedure ranges from $48 \%$ as reported by Takes et al to as high as $73 \%$ reported by van den Brekel et al. [76,77]. One of the reasons why sensitivities varied was the different criteria used in different studies on which nodes would be aspirated and evaluated. In an earlier study by Nieuwenhuis et al. [78], at least 1 lymph node was aspirated if the minimal diameter was at least $3 \mathrm{~mm}$. In a later study by Takes et al, in only nodes larger than $5 \mathrm{~mm}$ were aspirated. Righi et al in the United States had also used different criteria, whereby lymph nodes visualized on ultrasound were aspirated if they were $>7 \mathrm{~mm}$ in diameter, or met other suspicious criteria such as round lymph nodes, absence of a hilus, or focal cortical widening [79].

When US-guided fine-needle aspiration cytology is used for initial staging, and the same technique is employed during follow up, it may be possible to achieve tumor control comparable to elective treatment. Using this approach Nieuwenhuis reported a conversion rate of $20 \%$ when the clinically N0 neck was not treated electively, with $88 \%$ disease control of the neck after therapeutic neck dissection. In this way, patients would possibly be spared the elective treatment of the neck, thus potentially avoiding the associated complications and morbidities [80]. Some distinct advantages of this technique are its relatively low cost, lack of radiation exposure, easy availability, and the confirmation of sonographic findings by cytology [81]. There are still 2 major drawbacks of ultrasound, however; the fact that evaluation of level IIB nodes is limited secondary to their location [82], and the fact that this technique is extremely operator-sensitive and requires significant expertise to achieve proficiency [83]. Sampling errors of the aspirate are also known to contribute to false-negative results.

\section{Sentinel Node Biopsy}

In diseases such as breast cancer and malignant melanoma, sentinel node biopsy (SNB) is a mainstay in diagnosis and management. However its role in OSCC is still under investigation, and has made significant headway in the last decade. It allows 
for microscopic deposits of metastatic disease to be detected in cervical lymph nodes located within the drainage basin of a tumor, and thus aids in disease staging and therapeutic guidance. In this way, it potentially provides an alternative to END in diagnosis and staging of patients with early OSCC. Sentinel nodes (SN) are not necessarily the ones in closest proximity to the tumor, and more often than not, multiple SNs are present [84]. In this procedure, a syringe of a radionucleotide marker, consisting of filtered technetium sulfur colloid ( $99 \mathrm{mTc}$ ), is injected around the tumor bed.

Then lymphoscintigraphy using planar and/or SPECT/CT imaging is performed. Based on this, the position of the sentinel lymph node(s) is marked on the skin and intraoperative detection is possible by tumor injection of blue dye and using a portable gamma probe for radionucleotide detection. After surgical removal the sentinel nodes are examined histopathologically and by immunohistochemistry [85]. SNB is a very operatorsensitive technique, which does influence its efficacy. The negative predictive value for SNB is excellent, and is the number by which surgeons can assure that there is no presence of occult nodal disease, and ranges from 90-100\% (Table 1) [86-89]. However with that, false negatives are also of concern, allowing disease to go undetected, this was found to range from $5-13 \%$ for SNB, with sensitivities reported to be around 93\% [90].

Table 1: Sentinel node biopsy in oral squamous cell carcinoma.

\begin{tabular}{|c|c|c|c|c|}
\hline & $\begin{array}{c}\text { No. of } \\
\text { Patients }\end{array}$ & $\begin{array}{c}\text { SN ID Rate } \\
\text { (\%) }\end{array}$ & Sens (\%) & NPV (\%) \\
\hline $\begin{array}{c}\text { Alkureishi et al. } \\
\text { [90] }\end{array}$ & 79 & 91 & 87 & 95 \\
\hline $\begin{array}{c}\text { Broglie et al. } \\
\text { [87] }\end{array}$ & 58 & N/A & 91 & 90 \\
\hline $\begin{array}{c}\text { Samant et al. } \\
\text { [86] }\end{array}$ & 34 & 94.5 & 86 & 95 \\
\hline $\begin{array}{c}\text { Schilling et al. } \\
\text { [94] }\end{array}$ & 415 & N/A & 90 & 96 \\
\hline $\begin{array}{c}\text { Civantos et al. } \\
\text { [95] }\end{array}$ & 140 & 97 & 94 & 98 \\
\hline Pezier et al. [88] & 59 & 100 & 100 & 100 \\
\hline $\begin{array}{c}\text { Abdul-Rasak et } \\
\text { al. [96] }\end{array}$ & 30 & 98 & 93 \\
\hline
\end{tabular}

SN: sentinel node; Sens: sensitivity; NPV: negative predictive value.

The area of the mouth that presents the highest incidence of false negative results is the floor of the mouth. This is due to the effect of so-called "radiation shine-through", where the first echelon nodes are in such close proximity to the primary lesion that the radiation from the radio nucleotide marker around the lesion obscures that which is emitted from the nodes and thus are lost in the background, which decreases the sensitivity in FOM tumors to about $80 \%$ [91-93]. Despite this, a large multi-centre observational trial encompassing 14 European institutions (SENT study) including 415 patients found that the rate of false negatives in FOM oral SCC was only 14\% [94]. Moreover, they found that disease-specific survival for patients with early OSCC was $94 \%$, and found a negative predictive value of $95 \%$, the latter of which is in the range of most studies. The rate of regional recurrence in the neck was found to be 5\% in the SNB negative group, and 15\% in the SNB positive group, owing to minimal tumor spillage during the procedure.

In a large multi-center North American study by the American College of Surgeons Oncology Group (ACOSOG), the NPV was found to be $94 \%$ with a $9.8 \%$ false negative rate, confirming the conclusions reached by the SENT trial [95]. In a recent Australian prospective cohort study where 30 patients with T1 or T2 SCC of the oral tongue or FOM underwent SNB followed by immediate selective neck dissection, the NPV calculated was $100 \%$, and interestingly, $40 \%$ of sentinel nodes were identified outside of the field of planned neck dissection, with $8 \%$ of these being positive nodes, likely ones that would have been missed in standard END [96]. In the previously mentioned SENT study, $12 \%$ of SNs were found to be contralateral, with $6 \%$ of these being positive nodes harboring metastatic disease.

Moreoever, in another prospective study by Sagheb et al. [97] SNB was able to identify patients with a positive sentinel node at level IV of the ipsilateral neck, known as the "skip" metastasis, bypassing the upper levels of the neck, in patients with early SCC of the oral tongue [97]. Thus, the identification of aberrant patterns of lymphatic drainage and, therefore by extension, lymphatic tumor spread, remains a major advantage of SNB. The ability to identify nodes in the submental region may improve with Lymphoseek, which is a receptor-mediated lymphatic tracer that clears the injection site and concentrates within lymph nodes [98]. In a large prospective multicenter phase II trial by Miura et al, they found that the concordance of SNB with intraoperative frozen section analysis with final histopathology was 97.4\%, thus demonstrating the reliability of this technique [99]. More recently, the use of indocyanine green (ICG) has been tried in place of radioisotope tracers, combined with preoperative CT lymphography (CTL) for SN mapping, in early stage tongue cancer, and has shown promising results with $96.3 \%$ of SNs found by CTL and all were identified with intraoperative ICG [100].

Another distinct advantage of SNB is the potential to avoid overtreatment in a population of patients who may not need surgical intervention for the neck. An observational study by Stoeckle et al. [101] examined the use of SNB at the time of primary tumor resection, and in only the cases of a positive SNB performed a completion SND within 1 week, the purpose of which was to avoid overtreatment with immediate END in patients who did not require them. They found that they were able to avoid END in approximately $60 \%$ of patients with a neck recurrence rate of only $6 \%$ using SNB as the routine diagnostic and staging modality, which is very similar to recurrence rates related to END, and with the SNB technique showing very minimal morbidity [101]. 
The incidence shoulder dysfunction in END, despite sparing of the spinal accessory nerve is reported as 22 to $39 \%$ [102,103], and is avoided in SNB. In addition, the Stoeckli study also found that in $13 \%$ of patients who had lateral FOM and oral tongue SCC, the SNB was able to identify drainage to the contralateral nodes, as well as level IV nodes, which would have gone undiagnosed with a standard ipsilateral END as they would fall outside of the dissected area. Recently Schiefke et al analyzed the postoperative morbidity of SNB compared to END (specifically supraomohyoid neck dissection), looking at cervical scar, degree and extent of lymphedema, sensory dysfunction, facial and hypoglossal nerve function, cervical spine and shoulder dysfunction. Via clinical examination and quality of life questionnaires, they found that patients in the SNB group had clinically significantly less morbidity than the END group [104].

A recent cost-effectiveness study was carried out in which 5 different strategies for management of the clinically NO neck (defined in their study as NO after imaging and ultrasoundguided FNAC) in patients with OSCC. This study showed that the SNB followed by therapeutic neck dissection (if positive neck) or watchful waiting (if negative neck) is a more cost-effective treatment strategy than elective neck dissection, wait-and-see, gene expression profiling (GEP) followed by neck dissection (if high risk) and GEP and sentinel lymph node procedure (in case of high risk GEP) followed by neck dissection or watchful waiting [105].

Perhaps one of the most important aspects in all of this is the patient's viewpoint on diagnosis and management of their disease process. An interesting study was released in 2016 by a Flach et al. [106] in the Netherlands looking at specific patient factors such as psychological stress, anxiety, and depression, as well as the physical symptoms including pain, swallowing dysfunction, speech, sleep disturbances, and finally also looked at global functioning scales (social, emotional, physical, etc). This study found that $86 \%(19 / 22)$ of patients preferred the SNB strategy to END, and there was no difference in the emotional burden of presence of tumour in either group [106]. However it should be noted that the 3 patients who did prefer to go straight to the END were patients who initially were SNB+ and had to undergo a second procedure for the END. Thus it seems that despite END being the usual treatment of choice for most clinicians, SNB does present an interesting alternative.

\section{Management of the No Neck}

The management of the clinically negative neck in OSCC is a topic that has been studied and debated over decades in the literature. Many studies have attempted to elucidate the best treatment options when it comes to the clinically uninvolved neck, with many different methods of treatment available, however a consensus still eludes head and neck surgeons and oncologists. There have been many investigators and clinicians who are proponents of elective treatment of the neck, by way of either surgical treatment (i.e. elective neck dissection), or by non-surgical management, such as radiation therapy and possibly chemotherapy. The rationale behind elective treatment of the N0 neck lies in the following assumptions. First, that occult neck disease will eventually unequivocally become clinically evident disease, which will require treatment anyway, and possibly more extensive and morbid treatment.

The second is that the untreated undetected disease in the neck will increase the risk of distant metastasis, possibly developing the latter while the neck disease is growing into a clinically detectable entity. Others have advocated a "wait and see" philosophy, in which if a clinically node-negative neck is detected, elective treatment is not pursued, but rather kept on a close follow-up regimen and should the patient return with clinical neck involvement, a therapeutic treatment would be implemented, with surgery, radiation, chemotherapy, or a combination thereof. This policy is instituted to avoid subjecting a large number of patients to potentially unnecessary treatment with the complications that may ensue. However, with this, comes the potential of allowing a potentially undetected metastasis to remain present within the neck and the risk of a more extensive salvage therapy in the future.

\section{Surgical Therapy}

Surgical management of the neck in oral cancer has historically been by way of the neck dissection, which involves removal of fibro fatty tissue at multiple levels of the neck, which contains the lymphatic structures that could potentially harbour metastatic disease. In addition to this, other structures such as the spinal accessory nerve (SAN), internal jugular vein (IJV), sternocleidomastoid muscle (SCM) and other structures of the neck may be systematically removed in specific cases, depending on the extent of disease. Neck dissection was a concept that was first described by Crile in 1906 [107], with multiple variations having been developed over the $20^{\text {th }}$ century. The elective neck dissection serves as both a diagnostic and staging tool, as well as a therapeutic modality in the event that nodal metastasis is discovered on pathological evaluation.

Previously, the preferred method of treatment for patients with oral cancer with an N0 neck was radical neck dissection (RND) or modified radical neck dissection (MRND). However the necessity of such an extensive procedure has for the most part been abandoned, having been replaced by the selective neck dissection, done generally at time of primary tumour resection, in particular of levels I-III, also referred to as the supraomohyoid neck dissection [108]. A landmark paper on the topic was published by Weiss et al in 1994 [109], describing a systematic decision algorithm about treatment of the N0 neck based on a mathematically-derived formula. This was determined using a "time trade-off method" whereby surgeons determined the tradeoff between better quality of life and time of life given up for better 
function (Figure 1). Each of the branches of the tree were given series published from 1971 to 1984 [110-116]. probabilities for occurrence based on data from seven clinical

probabilities for occurrence bas

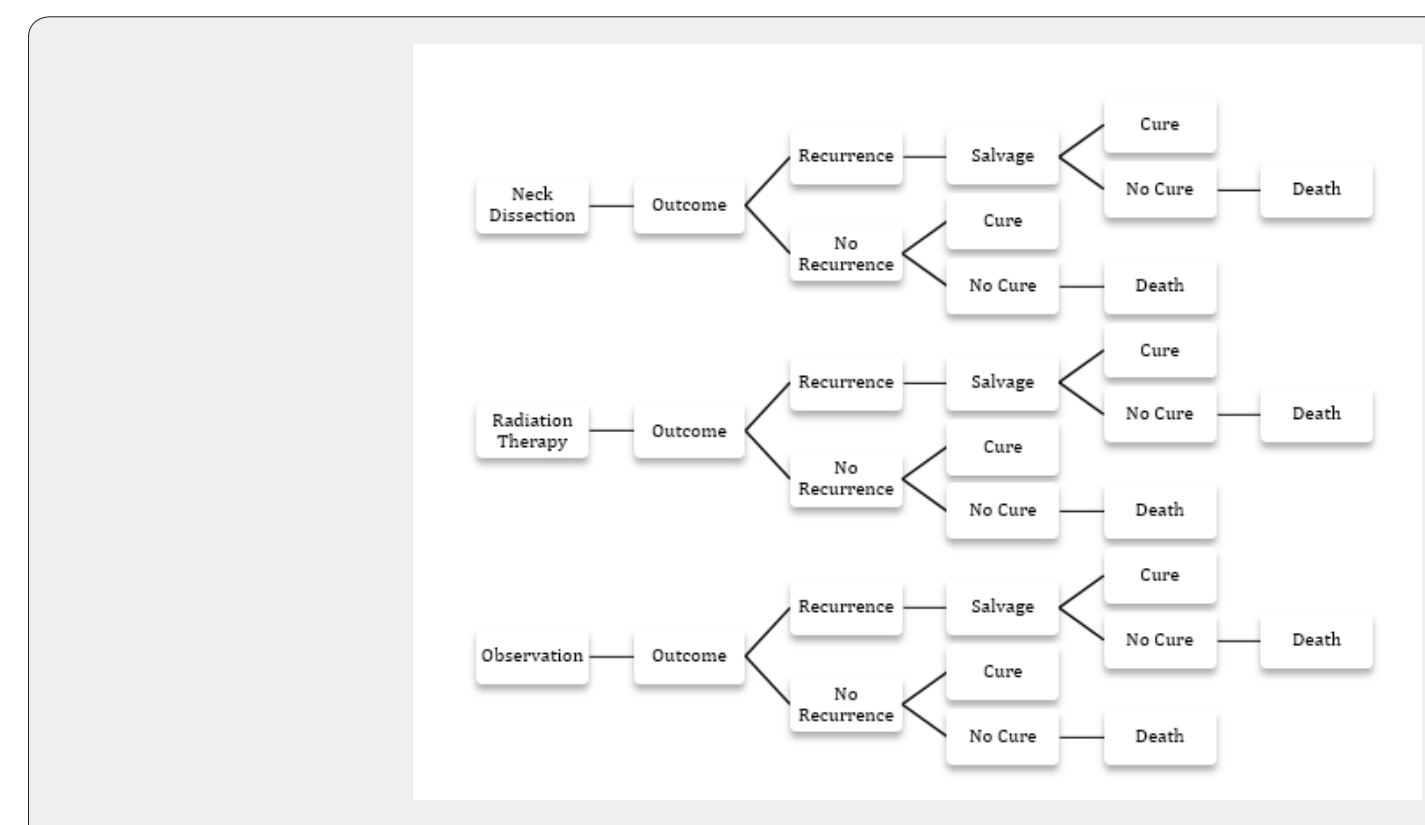

Figure 1: Computer-assisted decision analysis used by Weiss et al. Outcomes were given a probability of occurrence and desirability rating based on the time trade-off method [109].

The final outcomes were: cure, death, cure with surgery, cure with radiation, and cure with salvage, and these were all weighted according to desirability, based on the "time trade-off method". The conclusion of the study was that elective treatment of the neck was favourable only when the risk of occult metastasis to the neck exceeded $20 \%$. This number still represents the most commonly used threshold for treatment of the neck in early oral SCC a with a cN0 neck. Some authors more recently, however, have suggested lowering that threshold to $15 \%$ given the highly adverse effect of cervical lymph node metastasis on survival, as well as changes in the risk-benefit ratio during the past two decades due to the use of more conservative surgical procedures $[117,118]$.

A significant advantage of elective surgical treatment of the neck is that histological examination of the lymphatic tissue specimen is possible, enabling accurate pathological staging as well as producing other prognostic information, such as the presence of extracapsular spread (ECS) in involved nodes [119]. The importance of detecting ECS is well known, as this ominous finding is associated with an increased risk of locoregional failure, distant metastasis, and disease-specific death [120,121]. Studies have shown that though the risk of presence of ECS increases to $60-95 \%$ in nodes $>10 \mathrm{~mm}$ [122], even in nodes $<10 \mathrm{~mm}$ the risk is still significant, ranging from $17-48 \%$ [123].

Myers et al. [124] conducted a retrospective analysis of 266 patients with SCC of the oral tongue, and showed that the 5 -year disease-specific and overall survival of patients decreased significantly from $65 \%$ and $50 \%$ to $48 \%$ and $30 \%$ when ECS was detected on histopathological examination. Moreover, the study showed overall locoregional recurrence increased from $34.2 \%$ to $51.1 \%$, and distant metastasis rates went from $8.2 \%$ to $24.4 \%$ with the presence of ECS, thus highlighting the importance of providing lymphatic tissue for examination. In a study by Kreppel et al. [125] the prognostic significance of clinical (via physical examination and imaging) and histopathological staging was elucidated, and it was determined up to $46 \%$ of patients who were staged as cN0 preoperatively were found to have positive lymph node metastatic disease upon histological examination of the neck dissection specimen. In addition, a study by Koch et al found that pathological nodal evaluation was a better predictor of overall survival [126].

Several studies have shown optimized survival statistics after END in node-negative necks in oral cancer as compared to the "wait and see" policy employed by some centers, in particular when examining survival rates of neck metastasis that are only treated secondarily to the initial treatment [127-130]. SND ensures a high rate of regional disease control, and reports a cervical recurrence rate of $6 \%$, owing mainly to metastases developing outside the dissected area [131,132]. More recently, the landmark study by D'Cruz et al, a large prospective, randomized control trial with 596 patients with T1 or T2 OSCC over a 10-year period, compared END at the time of primary surgery with therapeutic neck dissection (TND) after a "watchful waiting" policy. This study found both an improved disease-free survival (69.5\% versus $45.9 \%$ ) and overall 
survival (80\% versus $67.5 \%$ ) in the END group, and represents a major support to this modality of management [133].

Kligerman et al conducted a prospective randomized study involving 67 patients staged $\mathrm{N} 0$ with $\mathrm{T} 1$ or $\mathrm{T} 2$ carcinoma of the oral cavity, and showed that the 3.5-year overall survival was $72 \%$ in the supraomohyoid neck dissection group, compared with $49 \%$ in the observation group, and advocated for END in all cases of early oral cancer [134]. Some investigators advocate for END only in $\mathrm{T} 2$ and higher lesions of the oral cavity, and recommend SNB in small T1 lesions with an N0 neck [135-137]. A meta-analysis by Oh et al showed a statistically significant difference in recurrence rate, overall as well as disease-specific survival in the END group at any stage, and this result has been echoed in other similar studies, regardless of the oral cavity subsite [138-140]. Moreover, Fasunla et al. [141] performed a meta-analysis of 4 randomized control trials (RCT) including 283 patients created another robust argument in favour of END in the clinically node-negative neck.

In this study, it was found that in the END group, nodal recurrence was detected in $6-30 \%$ of the patients, while in the observation group, nodal recurrence was detected in $37-58 \%$ of the patients, with disease-specific death rates ranging from 11 to $42 \%$ in the observation group, and 12 to $30 \%$ in the END group, which was found to be a statistically-significant difference in favor of END. Of note however, in all 4 of these RCTs, the tumor involved the oral tongue or FOM, both of which have been shown to inherently have a higher rate of cervical nodal metastasis than other sites in the oral cavity [142]. Some recent studies, though, have shown that the rate of cervical node metastasis of maxillary SCC approaches that of the tongue and FOM, from $28 \%$ for T2 lesions to $52 \%$ for $\mathrm{T} 4$ lesions, and as such have recommend that END be done at the time of primary tumor resection in patients with cancer of the maxillary oral mucosa that is T2 and above $[143,144]$.

Furthermore, in SCC of the hard palate, maxillary gingiva and alveolus, Montes and Schmidt demonstrated a $27 \%$ regional failure rate in clinically N0 neck after primary resection, and thus advocate for END in all cases of maxillary SCC [145]. Another study showed that there was no significant difference in overall survival or regional recurrence except in cases of locally advanced T4 maxillary lesions, where the 5-year survival was $81 \%$ for the END group and 56\% in the non-END group [146].

Interestingly, some authors advocate for bilateral neck dissections in cases of maxillary SCC that are T2 and above, as they found a $45.5 \%$ involvement of the contralateral neck despite tumors not approaching or crossing the midline [147]. One of the major drawbacks of primary surgical management is that potentially as many as $80 \%$ of patients are over treated with this approach, and may have benefited from more conservative management without adverse effect on outcome [148]. Moreover, if a salvage surgery is required, with the difficulty of re-operation of the neck, the success rate is only reported in the range of $30 \%$ in previously operated necks $[149,150]$, in addition to the fact that salvage operation would likely be more extensive, thus resulting in higher morbidity. However at least a part of the lower salvage success rates could be due to the presence of an inherently more aggressive disease process.

Tumour characteristics have been shown to influence cervical metastasis and thus must be discussed when deciding whether a neck dissection is necessary. Early on it was thought that tumour size was the most important variable, forming the basis of the AJCC tumour classification, however it has now been shown that tumour thickness or depth of invasion is the most important tumour characteristic influencing cervical metastasis and disease-specific survival, and forms one of the most important criteria for prescribing a neck dissection in T1-2 N0 disease [151]. This was first described by Spiro et al, reporting that tumors $<2 \mathrm{~mm}$ in thickness had very low incidence of disease-related death, regardless of tumor stage, however that incidence of neck metastasis approaches $40 \%$ with tumors $>2 \mathrm{~mm}$ [152].

Many subsequent studies have shown a strong correlation between thickness and cervical metastasis, but have used different cutoff values. Yuen, Kuan, and Vishak all used $3 \mathrm{~mm}$ as a cut off and reported a $50 \%$ to $63.3 \%$ cervical spread rate for any tumor measuring over 3mm [153-155]. Kurokawa et al used $4 \mathrm{~mm}$ and identified a $37.5 \%$ rate of cervical involvement [156]. A large number of studies have used $4 \mathrm{~mm}$ as their cutoff value and is now the most commonly used threshold for elective neck dissection in oral cancer [157-160]. Fukano et al recommended a 5mm cutoff value, owing to their finding that less than $5 \mathrm{~mm}$ thickness had a $5.9 \%$ rate of cervical metastasis [161].

A recent study in 2014 by Balasubramanian showed that $41.7 \%$ of floor of mouth (FOM) tumors showed nodal metastasis when $>2 \mathrm{~mm}$ thick, and thus advocate the use of this cutoff value specifically in FOM lesions [162]. In addition to tumor thickness, macroscopic tumor shape has also been looked at in relation to incidence of cervical metastasis. In a study by Shintani published in 1997, they divided tumors into superficial, endophytic, exophytic, and combination. They found that tumors with an expansive base showed significantly higher propensity for cervical metastasis than tumors with a reductive base, showing rates of $69.6 \%$ and $23.5 \%$ respectively.

One special consideration when discussing neck dissection in a clinically N0 neck in oral cancer is the inclusion of level IIB, otherwise known as the supraretrospinal triangle, supraspinal accessory lymph node pad, or submuscular recess [163] in the dissection. Historically this level has been removed, however with inclusion of this level comes the manipulation and possible skeletonization of the SAN, leading to ischemia and neuropraxia, accompanying with it the subsequent shoulder dysfunction postoperatively, as well as additional operating time. The 
question of the need to include this level in neck dissection has been questioned, due to its infrequent involvement in spread of oral cancer. In a meta-analysis of 9 studies performed by Lea et al. [164] in 2010, with a total of 332 patients included, the rate of micrometastasis to level IIB in the literature in the clinically N0 neck ranged from $0-10.4 \%$, with a mean of $6 \%$ [164].

However, it is noted that if a salvage surgery is required, removal of level IIB at the time of re-dissection may be significantly more difficult and may increase the risk of SAN damage. Thus despite the low rate of involvement of level IIB, Lea et al still recommend inclusion of this level in the original neck dissection. This is consistent with the recommendations of the majority of investigators [165-169]. In 2016 Bartella et al performed a retrospective analysis of 183 patients, finding that only $3.3 \%$ of patients exhibited spread to level IIB and advocate exclusion of this level in initial surgical dissection [170], unless the primary tumor is of the oral tongue, which has a higher propensity for involvement of this level [171]. The well-known shoulder syndrome that follows neck dissection is a significant cause of post-operative morbidity, and thus limiting manipulation of the SAN would be desirable if it is avoidable without compromising patient outcome.

In an interesting study by Erisen et al. [172] electromyographic (EMG) data was gathered on patients after undergoing SND, MRND, or RND, and it was shown that in all type of neck dissection, including supraomohyoid, some degree of electrophysiologic dysfunction was noted in the SAN thus leading to some degree of shoulder dysfunction. However did show that SND had better recovery rates than MRND and RND [172]. It seems that an increasing number of investigations are finding relatively infrequent involvement of level IIB in cases of N0 necks, and as such the potential of excluding this level in the initial dissection may be possible, thereby avoiding one of the more common postoperative patient complaints.

While dissection of levels I to III has become commonplace for the N0 neck in oral cancer, controversy still remains about level IV. In cases of cancers of the oral tongue, due to the higher incidence of neck metastasis, in particular the higher incidence of "skip" metastasis, authors have sometimes advocated dissection including level IV, or the "extended" supraomohyoid neck dissection, although this increases the incidence of chyle fistula and phrenic nerve injury [173-176]. While involvement of levels I to III has shown to yield a prevalence of close to $30 \%$ $[177,178]$, spread to level IV has been shown to be anywhere from $2 \%$ to $9 \%$, either by direct spread or by "skipping" first echelon nodes $[179,180]$. However, in a study by Byers et al, the authors showed a startling $15.8 \%$ involvement of level IV in cancer of the oral tongue, and advocated removal of that level in those cases involving the tongue [181].

Other studies have also shown a higher rate of spread to level IV in oral tongue cancer and have also advocated removal of this level $[182,183]$. Conversely, some investigators have found a much lower rate of spread to level IV, anywhere from $0 \%$ to $6.25 \%$ and recommend only level I to III dissection in cases of early oral tongue SCC [184-190]. The surgical anatomical distinction of level III versus level IV is the position of the omohyoid muscle. The discussion of whether to include level IV in the dissection may be one that is purely academic in nature, as studies have shown the great variability of the position of the muscle, as such having a direct influence on which the volume of lymphatic tissue that is removed from the neck. Some authors have even advocated to the abandonment of this landmark as a surgical guideline, owing to its variability in position and the fact that it does not represent an oncological barrier [191].

The density and course of lymphatic vessels leaving the primary tumor are what determine the direction of drainage and potential pathway of metastatic spread of the tumor [192,193]. As such, the accurate localization of the primary tumor serves as the primary variable in the decision of whether to perform a unilateral versus a bilateral neck dissection in patients with oral cancer. In patients whose tumors are bilateral or ones that evidently cross the midline, it is a well-known fact that bilateral neck dissection should be prescribed [194]. It is also recommended that for tumors that do not, upon gross visual inspection, violate the midline, but rather come close enough such that resection would require the surgeon to cross the midline to obtain an adequate surgical margin, should also undergo bilateral neck dissection [195].

\section{Chemoradiation}

The primary accepted modality for treatment of the N0 neck in oral cancer is surgical therapy by way of elective neck dissection. However non-operative management is also used in many head and neck centers. Radiation therapy has been employed in the treatment of oral cancer either as monotherapy or most commonly in the neoadjuvant or adjuvant setting. Chow et al. [196] analyzed 489 patients with primary head and neck cancers all with cN0 necks, and showed that no significant difference was noted with either elective neck dissection or elective neck radiation therapy in the treatment of subclinical cervical metastasis [196].

This result was also echoed in other retrospective analyses in controlling subclinical neck disease when the primary has been adequately controlled [197,198]. However despite this, traditionally radiation therapy has been reserved as a postoperative adjunctive treatment for patients who demonstrate certain adverse features such as pT3-4 disease, close or positive surgical margins, perineural invasion, extracapsular spread, lymphovascular invasion, or those who demonstrate a pN+ neck. Adjunctive radiotherapy has been shown to enhance locoregional control rates in cases of these adverse features [199].

Several factors must be considered when choosing treatment modalities for oral cancer: what is the treatment modality that 


\section{Global Journal of Otolaryngology}

will be employed for the primary tumor, patient age, medical co-morbidities, adverse effects of each therapy, the cost of each therapy, the facilities of the institution and the preferences and reliability of the patient. For instance, in patients undergoing surgical intervention for the primary tumor, it may be a convenient option to proceed simultaneously with surgical intervention of the neck as well, particularly when the neck must be entered anyway for preparation of vessels for microvascular reconstruction. On the other hand, in patients who choose not to have surgery, or are not surgical candidates, radiation therapy would be an option as definitive therapy, although it has not been shown to be as effective as surgery.

Several different modes of radiation therapy are available, and response rates have varied in the literature, showing different rates of disease control and recurrence. In a study by Wendt et al, 103 patients underwent definitive radiotherapy, both interstitial and external beam radiation, for stage I and II SCC of the oral tongue, and showed an $11 \%$ locoregional recurrence rate with delivery of 40Gy or more, as compared to $44 \%$ recurrence with no radiation of the N0 neck [200], while another study looked at external beam radiotherapy alone for definitive treatment of cancer of the retromolar trigone and reported a $0 \%$ locoregional recurrence rate after 2 years [201]. There have been several studies, which have employed interstitial radiation as monotherapy for early stage SCC of the oral cavity with excellent results, showing $80 \%$ or higher locoregional control [202-204].

Unfortunately, radiation therapy is also wrought with complications, many of which can have a significant impact of a patient's quality of life, often more than with surgical therapy [205-210]. Salvage therapy either by way of surgery or radiation in a previously irradiated site has not shown to have high rates of success. Side effects and complications of radiation treatment include xerostomia, skin changes, carotid artery [211] stenosis, speech and swallowing impairment, osteoradionecrosis (ORN) of the facial bones, subcutaneous fibrosis, as well as significant dental problems [212-214]. The extent of radiation therapy has a significant influence on development of complications, and as such, many studies have looked into the value of extensive radiotherapy with the possibility of decreasing exposure without compromising treatment success rates.

In a study by Spaulding et al [215] they showed a 95\% 3-year locoregional control rate with bilateral whole neck irradiation in early oral tongue cancer with an N0 neck, and when no radiation, partial bilateral, or only ipsilateral radiation was employed, only a 38\% control was achieved [215]. However in a more recent study, excellent disease control (92\% over 2 years) was noted by irradiating only ipsilateral levels I-IV and contralateral levels I and II in the radiated field, sparing the patient bilateral whole neck irradiation [216]. Other studies have also found similarly that ipsilateral irradiation results in uncompromised locoregional disease control without the resulting morbidity and affect on quality of life from permanent xerostomia from bilateral irradiation [217].

In recent years, the use of Intensity-Modulated Radiation Therapy (IMRT) has been studied both looking at its efficacy in relation to conventional radiotherapy as well as the potential for decreased post-irradiation complication rates. In a retrospective analysis of 145 patients, it was found that there was no significant difference in development of ORN with IMRT as compared to conventional radiation treatment, with $11 \%$ of patients in the conventional group developing ORN versus $10.2 \%$ in the IMRT group [218]. On the other hand, Duarte et al showed that IMRT was not only superior as far as decreasing the rate of ORN $(10.1 \%$ vs $0 \%$ ), but also showed decreased rates of xerostomia ( $46.5 \%$ vs $16.9 \%)$, mucositis ( $46.5 \%$ vs $16.9 \%)$, periodontal disease $(18.6 \%$ vs $27.3 \%)$, and radiation caries (15.2\% vs $20.3 \%)$, although the latter was not statistically significant [219]. Several other studies have also noted a decrease in complication rates when comparing the two radiation techniques, with IMRT showing improved quality of life data [220-222].

Cancer as we know is a genetic disorder, thus the ultimate success of any treatment will at least be partly dependent on the genetic makeup and behavior of the disease process. As such, the success or failure of radiation therapy hinges on the radiosensitivity of the cell lines within the tumor. It has been seen in several genetic studies that certain OSCCs have exhibited cell lines that are radioresistant, owing to overexpression of genes involved in anti-apoptosis and cell proliferation, in particular genes such as ID1, ID3, FGFR3, PEG10, ICAM2 and MMP13, which may contribute to radio-resistance that would significantly decrease effectiveness of radiation treatment among oral SCCs $[223,224]$. Once these genes have been definitively identified, the potential exists to use them as radio therapeutic molecular markers for targeted radiation therapy in the future, thus possibly dramatically increasing the effectiveness of treatment.

Systemic chemotherapy has been employed in treatment of advanced and metastatic cancer. However its use in cases of early oral cancer with a clinically negative neck has not been well established. In these cases, most often systemic therapy is reserved as a postoperative adjuvant measure if adverse features are found on pathological examination of lymph nodes, such as extracapsular spread or perineural invasion, as is commonly a platinum-based therapy, such as carboplatin or cisplatin. Patients demonstrating ECS should undergo more aggressive treatment with adjuvant chemotherapy in addition to external and interstitial beam radiation therapy $[225,226]$.

However induction or neoadjuvant chemotherapy as a preoperative modality has been studied by investigators, with the goal of reducing the extent and morbidity of subsequent local and regional therapy, both surgery and radiation, by way of cytoreduction, thus theoretically improving patient outcomes and quality of life. In a study by Licitra et al, a reduction in the extent of surgical intervention was observed, as $52 \%$ of patients in the 
control arm required segmental mandibulectomy, as compared to only $31 \%$ in the chemotherapy arm as a result of preoperative downstaging, without any positive margins detected. This study also found that fewer patients needed to undergo postoperative radiation therapy (33\%) as compared to $46 \%$ in the control arm.

However did not find any increase in overall survival. This result was also seen in a more recent large meta-analysis by Pignon et al. [227] finding that induction chemotherapy has no statistically significant increase in overall survival [227], but found that it decreased the rates of distant metastasis, possibly because higher doses delivered in typical induction regimens may be more effective at decreasing later distant metastases than chemotherapy given at lower doses concurrent to postoperative radiotherapy. This study also concluded that the concomitant use of chemotherapy with loco-regional treatment modalities had a $5 \%$ increase in overall survival and lower rates of loco-regional failure [228,229].

The use of systemic chemotherapy is most often employed in locally advanced cancers, however, it has also been shown that when used in earlier staged lesions, tumour response has been better, specifically in T1 and T2 tumors [230]. Neoadjuvant combination of radio chemotherapy, RADPLAT, followed by surgery has also been established in several head and neck centres, and has resulted promising overall and disease-free survival rates with tolerable adverse effects [231,233]. In addition, concurrent chemotherapy as a radiosensitizer is known to increase tumor control [234,235]. Despite some encouraging recent data, induction and concomitant chemotherapy has not gained widespread use as of yet, and will undoubtedly continue to be studied.

\section{"Wait-and-See"}

Elective therapy of the neck carries with it inherent complications and morbidities. In view of this, many head and neck centers have adopted a "wait-and-see" policy in management of the neck in cases of early oral cancer with a cNO neck, particularly in those cases where the risk of neck involvement is deemed less than $20 \%$, with the goal of avoiding overtreatment of patients and only employing therapeutic measures only if nodal involvement presents. Close follow-up is employed with periodic head and neck examination via palpation and ultrasound-guided FNAC. In some institutions, additional use of lymphoscintigraphy for identification of sentinel nodes is used on follow-up, where SNs are identified and aspirated under ultrasound guidance to decrease the rate of false negatives [236].

Despite this, several studies in the literature have shown distinct overall survival and disease-free survival statistics in the END groups as compared to observation groups. In a retrospective review by Lydiatt et al of 156 patients with $\mathrm{T} 1$ and $\mathrm{T} 2$ carcinoma of the tongue staged $\mathrm{N} 0$, they demonstrated that when elective neck dissection was carried out together with glossectomy, the survival rate was 55\% compared with 33\% when the neck was observed [237]. Yuen et al reported that the regional failure rate was $9 \%$ in the END group compared to $47 \%$ in the observation group and, moreover, the 5 -year disease-free survival rate was also considerably higher at $86 \%$ in the END group and $55 \%$ in the patients undergoing observation [238].

Despite this data, more recently some studies have shown that there is no survival advantage to elective neck dissection versus observation [239], and others have shown that the watch and wait methodology showed favorable results in patients with very early T1N0M0 OSCC, with close follow-up, showing a 100\% diseasespecific survival over 5 years [240]. In a recent prospective randomized study of patients with early oral tongue carcinoma, Yuen et al found no significant difference in disease-free survival in either group, a finding not previously found in his study two decades earlier.

While some head and neck surgeons feel that the N0 neck can be readily observed and treated when the patient develops $\mathrm{N} 1$ metastatic disease, this is not always the case. Although it appears intuitive that the N0 neck will pass through the N1 stage before progressing to N2 or N3 disease, it is not uncommon for patients undergoing the "wait-and-see" protocol to present with N2 and N3 disease despite close surveillance. In a study by Andersen et al. [241], $60 \%$ of patients with an initial N0 neck undergoing observation, presented with pathologically N2 disease on followup in the form of multiple positive nodes or extracapsular extension (49\%), despite aggressive surveillance schedules. Thus in these cases, not only would the patient require more aggressive salvage surgical intervention by way of MRND or RND, but they may also require neoadjuvant or adjuvant Chemoradiation [242].

Moreover, salvage therapy success rates in these situations have been quite poor, at approximately 30\% [243,244]. Patient compliance as well as social factors play an important role in "wait and see" management, as noncompliance with a strict surveillance schedule would undoubtedly result in an increase in the failure rate. A study from a high volume cancer center in India found that the compliance of head and neck cancer patients for treatment was only $56 \%$, which is, needless to say, a concerning statistic [245]. Therefore, high rates of occult metastases in the untreated neck, disease presenting in advanced stages after observation, poor salvage rates for failures at the level of the neck, and patient compliance issues have prompted many investigators to continue to propose elective treatment of the N0 neck as opposed to the "wait and see" with therapeutic treatment of the neck when nodal metastasis presents [246-249].

\section{Future Advances}

Accurate diagnosis and management of the neck in oral SCC remains suboptimal despite advances in imaging technologies and surgical therapy, as a reliable predictor of cervical metastasis still eludes us. Current research is investigating the role of 


\section{Global Journal of Otolaryngology}

gene expression profiling of tumor biopsies in order to identify molecular markers that would help determine the propensity of lymphatic spread to the neck of a particular lesion, thereby offering a patient-specific evaluation of disease behavior, thus allowing clinicians to specifically tailor a treatment regimen to each patient, rather than relying on general treatment algorithms (Table 2) [250-258].

Table 2: Molecular markers for predicting oncological behaviour.

\begin{tabular}{|c|c|}
\hline GIRK 1 & Overexpressed in metastatic breast cancer \\
\hline $\begin{array}{c}\text { Vacuolar ATP syn- } \\
\text { thase subunit C }\end{array}$ & $\begin{array}{c}\text { Increased levels in metastatic pancreatic } \\
\text { cancer }\end{array}$ \\
\hline Cyclin D1 & $\begin{array}{c}\text { Overexpressed in 68\% of OSCC with lymphatic } \\
\text { spread }\end{array}$ \\
\hline MMP-9 & Increased metastasis of H\&N SCC \\
\hline uPA & Increased in metastatic breast cancer \\
\hline E-Cadherin & Decreased levels correlates with metastatic \\
phenotype
\end{tabular}

Many of these genes have been identified not only in OSCC, but also in aggressive phenotypes of other types of cancers, including breast and pancreatic neoplasms. In a Dutch multicenter study of 101 early (cN0) OSCC, gene expression profiles were assessed by microarray hybridization and achieved a NPV of 89\%, allowing for a "wait and see" policy to be instituted for those patients; however, the PPV in this study was only $37 \%$, thus almost twothirds of patients would undergo unnecessary treatment of the neck if only this was relied upon [259]. In their study, O'Donnell et al were able to locate differences in expression of immune cells in node-positive versus node-negative OSCC, specifically HLA II DO beta and CD64, hypothesizing that differences in the genetic make-up of the host, through immune or stromal cell interaction with the tumor, may be a critical factor in progression from a nonaggressive, non-metastatic phenotype to an aggressive, metastatic one [260].

Unfortunately, due to the immense heterogeneity of the genetic profile of different tumors, the consistency of the presence or absence of certain molecular markers varies, thus decreasing their reliability. The $7^{\text {th }}$ edition of the American Joint Commission on Cancer (AJCC) Staging for Head and Neck Cancer has been criticized for failing to account for the depth of invasion (DOI) and extranodal spread (ENS), two critical factors with significant prognostic and therapeutic implications. As a result, the 8th edition of the AJCC Staging Manual has now implemented major changes for the tumour (T) and Nodal (N) staging for oral cavity carcinoma including DOI and ENS, respectively [261]. In addition, the HPV status is now incorporated into the new staging system for oropharyngeal carcinoma. These changes will not only eliminate confusion among the clinicians and the general population but also better reflect the prognosis and treatment requirement for each stage. For example, oropharyngeal carcinoma patients with a positive HPV status may qualify for de-escalated radiation therapy based on the future research.

\section{Conclusion}

The debate over the management of the clinically nodenegative neck in oral squamous cell carcinoma is one that has spanned many decades. Unfortunately at present the adequacy of diagnostic and staging modalities is still lacking and requires further investigation. Currently advancements in imaging modalities have provided varying degrees of diagnostic accuracy in the literature, both in the initial stages of disease stratification as well as follow-up imaging during observation periods. Sentinel lymph node biopsy has shown several advantages and has gained popularity in Europe and is beginning to be used more and more in head and neck centres in North America.

Elective surgical management of early OSCC remains the most widespread treatment modality utilized by clinicians, with adjunctive therapies usually reserved for more advanced cases or in the presence of adverse histological or clinical features. The popularity of the "wait and see" methodology has grown over the years, however with the risk of more extensive salvage surgery in the future, without consistent evidence of its clear advantage over elective therapy, and the minimal morbidity offered by selective neck dissection, it remains a secondary treatment consideration.

There is a strong need for randomized control trials to provide level I and II evidence for potential treatment strategies, as currently much of the literature is retrospective in nature. It has also been demonstrated that there are site-specific differences in clinical behaviour within the oral cavity and further extrapolation would be beneficial. Advances in molecular analysis and genetically-guided therapy have shown to potentially have a significant impact in determining clinical behaviour and therefore on the treatment of cancer, and certainly represents the future in the management of this disease.

\section{References}

1. Shah JP, Patel SG (2003) Head and neck Surgery and Oncology. (3 $3^{\text {rd }}$ edn), pp. 173-233.

2. Kazi RA (200) The life and Times of George Washington Crile: An Outstanding Surgeon. The internet J of Otorhinolaryngology 2: 2 .

3. Lambert R, Sauvaget C, De Camargo Cancela M (2011) Epidemiology of cancer from the oral cavity and oropharynx. Eur J Gastroenterol Hepatol 23: 633-641.

4. Burzlaff JB, Bohrer PL (2007) Exposure to alcohol or tobacco affects the pattern of maturation in oral mucosal cells: a cytohistological study. Cytopathology 18(6): 367-375.

5. Boeing $\mathrm{H}$ (2002) Alcohol and risk of cancer of the upper gastrointestinal tract: first analysis of the EPIC data. EPIC Working Group on Dietary Patterns. IARC Sci Publ 156: 151-154.

6. Freedman ND, Schatzkin A (2007) Alcohol and head and neck cancer risk in a prospective study. Br J Cancer 96(9): 1469-1474.

7. Goldstein BY, Change SC (2010) Alcohol consumption and cancers of the oral cavity and pharynx from 1988 to 2009: an update. Eur J Cancer Prev 19(6): 431-465. 


\section{Global Journal of Otolaryngology}

8. Fielding LP, Fenoglio Preiser CM, Freedman LS (1992) The future of prognostic factors in outcome prediction for patients with cancer. Cancer 70(9): 2367-2377.

9. Kowalski LP, Magrin J, Waksman G (1993) Supraomohyoid neck dissection in the treatment of head and neck tumors. Survival results in 212 cases. Arch Otolaryngol Head Neck Surg 119(9): 958-963.

10. Leemans CR, Tiwari R (1993) Regional lymph node involvement and its significance in the development of distant metastases in head and neck carcinoma. Cancer 71(2): 452-456.

11. Shah JP, Andersen PE (1995) Evolving role of modifications in neck dissection for oral squamous carcinoma. Br J Oral Maxillofac Surg 33(1): 3-8.

12. Clark JR, Naranjo N, Franklin JH (2006) Established prognostic variables in N0 oral carcinoma. Otolaryngol Head Neck Surg 135(5): 748-753.

13. Zbaren P, Nuyens M, Caversaccio M (2006) Elective neck dissection for carcinomas of the oral cavity: occult metastases, neck recurrences, and adjuvant treatment of pathologically positive necks. Am J Surg 191(6): 756-760.

14. O'Brien CJ, Traynor SJ, McNeil E (2000) The use of clinical criteria alone in the management of the clinically negative neck among patients with squamous cell carcinoma of the oral cavity and oropharynx. Arch Otolaryngol Head Neck Surg 126(3): 360-365.

15. Okada Y, Mataga I, Katagiri M (2003) An analysis of cervical lymph nodes metastasis in oral squamous cell carcinoma. Relationship between grade of histopathological malignancy and lymph nodes metastasis. Int J Oral Maxillofac Surg 32(3): 284-288.

16. Spiro JD, Spiro RH, Shah JP (1988) Critical assessment of supraomohyoid neck dissection. AmJ Surg 156(4): 286-289.

17. Woolgar JA (1999) Histological distribution of cervical lymph node metastases from intraoral/ oropharyngeal squamous cell carcinomas. Br J Oral Maxillofac Surg 37: 205-209.

18. Yu S, Li J, Li Z (2006) Efficacy of supraomohyoid neck dissection in patients with oral squamous cell carcinoma and negative neck. Am J Surg 191(1): 94-99.

19. Robbins KT (2000) Indications for selective neck dissection: when, how, and why. Oncology 14: 1455-1469.

20. Shiga K, Ogawa T, Sagai S, Kato K (2007) Management of the patients with early stage oral tongue cancers. Tohoku J Exp Med 212: 389-396.

21. Genden E, Ferlito A (2003) Complications of Neck Dissection. Acta Otolaryngol 123: 705-801.

22. Hosal AS, Carrau RL, Johnson JT (2000) Selective neck dissection in the management of the clinicallynode-negative neck. Laryngoscope 110(12): 2037-2040.

23. Nahum AM, Mullally W, Marmor L (1961) A syndrome resulting from radical neck dissection. Arch Otolaryngol 74: 424-428.

24. Kowalski LP, Magrin J, Waksman G (1993) Supraomohyoid neck dissection in the treatment of head and neck tumors. Survival results in 212 cases. Arch Otolaryngol Head Neck Surg 119(9): 958-963.

25. Kubicek GJ, Champ C, Fogh S (2010) FDG-PET staging and importance of lymph node SUV in head and neck cancer. Head Neck Oncol 2: 19.

26. De Zinis LO, Bolzoni A, Piazza C, Nicolai P (2006) Prevalence and localization of nodal metastases in squamous cell carcinoma of the oral cavity: role and extension of neck dissection. Eur Arch Otorhinolaryngol 263: 1131-1135.

27. Castelijns JA, Van Den Brekel MW (2002) Imaging of lymphadenopathy in the neck. Eur Radiol 12(4): 727-738.

28. Van Den Brekel MW, Castelijns JA (2005) What the clinician wants to know: surgical perspective and ultrasound for lymph node imaging of the neck. Cancer Imaging 5(Spec No A): S41-S49.

29. Woolgar JA, Vaughan ED, Scott J (1994) Pathological findings in clinically false-negative and false positive neck dissections for oral carcinoma. Ann R Coll Surg Engl 76(4): 237-244.

30. Close LG, Merkel M, Vuitch MF, Reisch J (1989) Computed tomographic evaluation of regional lymph node involvement in cancer of the oral cavity and oropharynx. Head Neck 11: 309-317.

31. Friedman M, Mafee MF, Pacella BL, Strorigl TL (1990) Rationale for elective neck dissection in 1990. Laryngoscope 100: 54-59.

32. Lenz M, Kersting Sommerhoff B, Gross M (1993) Diagnosis and treatment of the N0 neck in carcinomas of the upper aerodigestive tract: current status of diagnostic procedures. Eur Arch Otolaryngology 250: 432-438.

33. Stevens MH, Harnsberger HR, Mancuso AA (1985) Computed tomography of cervical lymph nodes. Staging and management of head and neck cancer. Arch Otolaryngol 111: 735-739.

34. Baatenburg de jong RJ, Rongen RJ, Lameris JS (1989) Palpation vs ultrasound examination. Arch Otolaryngol Head Neck Surg 115: 689690 .

35. Hannah A, Scott AM, Tochon Danguy H (2002) Evaluation of 18 F-fluorodeoxyglucose positron emission tomography and computed tomography with histopathologic correlation in the initial staging of head and neck cancer. Ann Surg 236(2): 208-217.

36. Stuckensen T, Kovács AF, Adams S, Baum RP (2000) Staging of the neck in patients with oral cavity squamous cell carcinomas: a prospective comparison of PET, ultrasound, CT and MRI. J of Craniomaxillofac Surg 28: 319-324.

37. Dammann F, Horger M, Mueller Berg M (2005) Rational diagnosis of squamous cell carcinoma of the head and neck region: comparative evaluation of CT, MRI, and 18FDG PET. AJR Am J Roentgenol 184: 13261331.

38. To EW, Tsang WM, Cheng J (2003) Is neck ultrasound necessary for early stage oral tongue carcinoma with clinically N0 neck? Dentomaxillofac Radiol 32: 156-159.

39. Van den Brekel MW, Stel HV, Castelijns JA (1990) Cervical lymph node metastasis: assessment of radiologic criteria. Radiology 177: 379-384.

40. Wei W, Ferlito A (2006) Management of the N0 neck-reference or preference? Oral Oncology 42: 115-122.

41. Schoder H, Carlson DL, Kraus DH (2006) 18F-FDG PET/CT for detecting nodal metastases in patients with oral cancer staged N0 by clinical examination and CT/MRI. J Nucl Med 47(5): 755-762.

42. Ferlito A, Shaha AR, Rinaldo A (2002) The incidence of lymph node micrometastases in patients pathologically staged N0 in cancer of oral cavity and oropharynx. Oral Oncol 38: 3-5.

43. Van Den Brekel MWM, Van Der Waal I (1996) The incidence of micrometastases in neck dissection specimens obtained from elective neck dissections. Laryngoscope 106: 987-991.

44. Shingaki S, Suzuki I, Nakajima T (1995) Computed tomographic evaluation of lymph node metastasis in head and neck carcinomas. J Craniomaxillofac Surg 23: 233-237.

45. Steinkamp HJ, Hosten N, Richter C (1994) Enlarged cervical lymph nodes at helical CT. Radiology 191: 795-798.

46. Schuller DE, Bier Laning CM, Sharma PK (1998) Tissue conserving 


\section{Global Journal of Otolaryngology}

surgery for prognosis, treatment, and function preservation. Laryngoscope 108: 1599-1604

47. Matakazu F, Dillon J, Futran N (2014) The prevalence of lymph node metastases in clinically N0 necks with oral cavity squamous cel carcinoma: is CT good enough for nodal staging. Acta Radiologica 55(5): 570-578.

48. Ferlito A, Partridge M, Brennan J, Hamakawa H (2001) Lymph node micrometastases in head and neck cancer: a review. Acta Otolaryngol 121: 660-665.

49. Rinaldo A, Devaney KO, Ferlito A (2004) Immunohistochemical studies in the identification of lymph node micrometastases in patients with squamous cell carcinoma of the head and neck. ORL J Otorhinolaryngol Relat Spec 66: 38-41.

50. Brennan JA, Mao L, Hruban RH, Boyle JO, Eby YJ, et al. (1995) Molecular assessment of histopathological staging in squamous-cell carcinoma of the head and neck. N Engl J Med 332: 429-435.

51. Hamakawa H, Fukizumi M, Bao Y, Sumida T, Onishi A (1999) Genetic diagnosis of micrometastasis based on SCC antigen mRNA in cervical lymph nodes of head and neck cancer. Clin Exp Metastasis 17: 593-599.

52. Cortesina G, Martone T, Galeazzi E, Olivero M (2000) Staging of head and neck squamous cell carcinoma using the MET oncogene product as marker of tumor cells in lymph node metastases. Int J Cancer 89 286-292.

53. Nieuwenhuis EJ, Leemans CR, Kummer JA, Denkers F, Snow RH (2003) Assessment and clinical significance of micrometastases in lymph nodes of head and neck cancer patients detected by E48 (Ly-6D) quantitative reverse transcription-polymerase chain reaction. Lab Invest 83: 1233-1240.

54. Wu L, Cao Y, Liao C, Huang J, Gao F (2011) Diagnostic performance of USPIO-enhanced MRI for lymph node metastases in different body regions: a meta-analysis. Eur J Radiol 80: 582-589.

55. Sigal R, Vogl T, Casselman J (2002) Lymph node metastases from head and neck squamous cell carcinoma: MR imaging with ultrasmall superparamagnetic iron oxide particles (Sinerem MR) - results of a phase-III multicenter clinical trial. Eur Radiol 12: 1104-1113.

56. Adams S, Baum RP, Stuckensen T, Bitter K, Hör G (1998) Prospective comparison of 18F-FDG PET with conventional imaging modalities (CT, MRI, US) in lymph node staging of head and neck cancer. Eur J Nuc Med 25: 1255-1260.

57. Ng SH, Yen TC, Liao CT (2005) 18F-FDG PET and CT/MRI in oral cavity squamous cell carcinoma: a prospective study of 124 patients with histologic correlation. J Nucl Med 46: 1136-1143.

58. Di Martino E, Nowak B, Hassan HA (2000) Diagnosis and staging of head and neck cancer: a comparison of modern imaging modalities (positron emission tomography, computed tomography, color-coded duplex sonography) with panendoscopic and histopathologic findings. Arch Otolaryngol Head Neck Surg 126(12): 1457-1461.

59. Stoeckli SJ, Steinert H, Pfaltz M, Schmid S (2002) Is there a role for positron emission tomography with $18 \mathrm{~F}$-fluorodeoxyglucose in the initial staging of nodal negative oral and oropharyngeal squamous cell carcinoma? Head Neck 24: 345-349.

60. Hyde NC, Prvulovich E, Newman L, Waddington WA (2003) A new approach to pre-treatment assessment of the N0 neck in oral squamous cell carcinoma: the role of sentinel node biopsy and positron emission tomography. Oral Oncol 39: 350-360.

61. Schroeder U, Dietlin M. Is There a Need for Positron Emission Tomography Imaging to Stage the N0 Neck in T1-T2 Squamous Cell Carcinoma of the Oral Cavity or Oropharynx? Annals of Otology,
Rhinology \& Laryngology 117(11): 854-863.

62. Myers LL, Wax MK (1998) Positron emission tomography in the evaluation of the negative neck in patients with oral cavity cancer. J Otolaryngol 27(6): 342-347.

63. Brouwer J, de Bree R, Comans EF, Castelijns JA, Hoekstra OS, et al (2004) Positron emission tomography using [18F] fluorodeoxyglucose (FDG-PET) in the clinically negative neck: is it likely to be superior? Eur Arch Otorhinolaryngol 261(9): 479-483.

64. Schoder H, Carlson DL, Kraus DH, Stambuk HE, Gonen M, et al. (2006) 18F-FDG PET/CT for detecting nodal metastases in patients with oral cancer staged N0 by clinical examination and CT/MRI. J Nucl Med 47(5): 755-762.

65. Krabbe CA, Djikstra PU (2008) FDG PET in oral and oropharyngeal cancer. Value for confirmation of N0 neck and detection of occult metastases. Oral Oncology 44: 31-36.

66. Kau RJ, Alexiou C, Laubenbacher C (1999) Lymph node detection of head and neck squamous cell carcinomas by positron emission tomography with fluorodeoxyglucose F-18 in a routine clinical setting. Arch Otolaryngol Head Neck Surg 125: 1322-1328.

67. Jeong HS, Baek CH, Son YI (2007) Use of integrated 18F-FDG PET/CT to improve the accuracy of initial cervical nodal evaluation in patients with head and neck squamous cell carcinoma. Head Neck 29: 203-210.

68. Ng SH, Yen TC, Chang JT (2006) Prospective study of '18F'fluorodeoxyglucose positron emission tomography and computed tomography and magnetic resonance imaging in oral cavity squamous cell carcinoma with palpably negative neck. J Clin Oncol 24: 4371-4376.

69. Ozer E (2012) The value of PET/CT to assess clinically negative necks Eur Arch Otorhinolaryngol 269: 2411-2414.

70. Cetin B, Atasever T, Akdemir UO (2013) The role of positron emission tomography with $18 \mathrm{~F}$-fluorodeoxyglucose in nodal staging of clinical and radiological N0 head and neck cancers. Eur Arch Otorhinolaryngol 270: 2307-2313.

71. Schaefferkoetter JD, Carlson ER (2015) Can 3'-Deoxy-3'-(18F) Fluorothymidine Out Perform 2-Deoxy-2-(18F) Fluoro-D-Glucose Positron Emission Tomography/Computed Tomography in the Diagnosis of Cervical Lymphadenopathy in Patients With Oral/Head and Neck Cancer? J Oral Maxillofac Surg 73: 1420-1428.

72. Borgemeester M, Van den Brekel MWM (2008) Ultrasound-guided Aspiration Cytology for The Assessment of the Clinically NO Neck: Factors Influencing its Accuracy. Head Neck 30: 1505-1513.

73. Stoeckli SJ, Haerle SK, Strobel K, Haile SR, Hany TF (2012) Initial staging of the neck in head and neck squamous cell carcinoma: a comparison of CT, PET/CT, and ultrasound-guided fine-needle aspiration cytology. Head Neck 34: 469-476.

74. Heusch P, Sproll C, Buchbender C (2014) Diagnostic accuracy of ultrasound, 18F-FDG-PET/CT, and fused 18F-FDG-PET-MR images with DWI for the detection of cervical lymph node metastases of HNSCC. Clin Oral Investig 18: 969-678.

75. Van den Brekel MW, Castelijns JA, Snow GB (1998) The size of lymph nodes in the neck on sonograms as a radiologic criterion for metastasis: how reliable is it? AJNR Am J Neuroradiol 19: 695-700.

76. Van den Brekel MWM, Castelijns JA, Stel HV (1993) Modern imaging techniques and ultrasound-guided aspiration cytology for the assessment of neck node metastases: a prospective comparative study. Eur Arch Otolaryngology 250: 11-17.

77. Takes RP, Righi P, Meeuwis CA (1998) The value of ultrasound with ultrasound-guided fine-needle aspiration biopsy compared to 


\section{Global Journal of Otolaryngology}

computed tomography in the detection of regional metastases in the clinically negative neck. Int J Radiat Oncol Biol Phys 40: 1027-1032.

78. Nieuwenhuis EJC, Castelijns JA, Pijpers R (2002) Wait and see policy for the N0 neck in early-stage oral and orapharyngeal squamous cell carcinoma using ultrasonography-guided cytology: is there a role for identification of the sentinel node? Head Neck 24: 282-289.

79. Righi PD, Kopecky KK, Caldemeyer KS (1997) Comparison of ultrasound fine needle aspiration and computed tomography in patients undergoing elective neck dissection. Head Neck 19(7): 604610.

80. Leemans CR (2002) Controversy on the management of the clinically negative neck. In: Matos de Sa' G, Kligerman J, Lima RA, Dias FL, Marques Barbosa MM (Eds.), $2^{\text {nd }}$ World Congress of the International Federation of Head and Neck Oncologic Societies Pp 51-58.

81. Bree RD (2015) Advances in diagnostic modalities to detect occult lymph node metastases in head and neck squamous cell carcinoma. Head Neck 37: 1829-1839.

82. Hohlweg-Majert B, Metzger MC, Voss PJ, Holzle F,Wolff KD (2009) Preoperative cervical lymph node size evaluation in patients with malignant head/neck tumors: comparison between ultrasound and computer tomography. J Cancer Res Clin Oncol 135: 753-759.

83. Kaahling C, Langguth T (2016) A retrospective analysis of preoperative staging modalities for oral squamous cell carcinoma. Journal of CranioMaxillo-Facial Surgery 44(12): 1952-1956.

84. BNMS Clinical Guidelines (2015).

85. 1 LW, Burak Z, Alvarez JA (2009) Joint practice guidelines for radionuclide lymphoscintigraphy for sentinel node localization in oral/oropharyngeal squamous cell carcinoma. Ann Surg Oncol 16(11): 3190-3210.

86. Samant S (2014) Sentinel node biopsy as an alternative to elective neck dissection for staging of early oral carcinoma. Head Neck 36(2): 241 246

87. Broglie MA, Haile SR, Stoeckli SJ (2011) Long-term experience in sentinel node biopsy for early oral and oropharyngeal squamous cell carcinoma. Ann Surg Oncol 18(10): 2732-2738.

88. Pezier T, Nixon IJ, Gurney B (2012) Sentinel lymph node biopsy for T1/ T2 oral cavity squamous cell carcinoma-a prospective case series. Ann Surg Oncol 19(11): 3528-3533.

89. Abdul RM, Chung H, Wong E (2017) Sentinel lymph node biopsy for early oral cancers: Westmead hospital experience. Anz J Surg 87(1-2): 65-69.

90. Alkureishi LW, Ross GL, Shoaib T, Soutar DS, Robertson AG, et al. (2010) Sentinel node biopsy in head and neck squamous cell cancer: 5-year follow up of a European multicenter trial. Ann Surg Oncol 17(9): 24592464 .

91. Shoaib T, Soutar DS, Prosser JE, Dunaway DJ, Gray HW (1999) A suggested method for sentinel node biopsy in squamous cell carcinoma of the head and neck. Head Neck 21: 728-733.

92. Ross GL, Soutar DS, Gordon MD, Shoaib T (2004) Sentinel node biopsy in head and neck cancer: preliminary results of a multicenter trial. Ann Surg Oncol 11: 690-696.

93. Alvarez J, Bidaguren M, McGurk G, Diaz BJ (2014) Sentinel node biopsy in relation to survival in floor of the mouth carcinoma. Int J Oral Maxillofac Surg 43(3): 269-273.

94. Schilling C, Stoeckli SJ, Haerle SK (2015) Sentinel European Node Trial (SENT): 3-year results of sentinel node biopsy in oral cancer. Eur J Cancer 51(18): 2777-2784.

95. Civantos FJ, Zitsch RP, Schuller DE (2010) Sentinel lymph node biopsy accurately stages the regional lymph nodes for T1-T2 oral squamous cell carcinomas: results of a prospective multi-institutional trial. J Clin Oncol 28(8): 1395-1400.

96. Abdul RM, Chung H, Wong E (2017) Sentinel lymph node biopsy for early oral cancers: Westmead Hospital experience. ANZ J Surg 87(1-2): 65-69.

97. Sagheb K, Sagheb, K, Rahimi NR (2016) Sentinel lymph node biopsy in $\mathrm{T} 1 / \mathrm{T} 2$ squamous cell carcinomas of the tongue: A prospective study. Oncology Letters 11(1): 600-604.

98. Agrawal A, Civantos FJ, Brumund KT (2015) 99m TC Tilmanocept accurately detects seninel lymph nodes and predicts node pathology status in patients with oral squamous cell carcinoa of the head and neck: results of a phase III multi-institutional trial. Ann Sug Oncol 22(11): 3708-3715

99. Miua K, Hirakawa H, Uemura H (2017) Sentinel node biopsy for oral cancer: A prospective multicenter Phase II trial. Auris Nasus Larynx 44(3): 319-326.

100. Ishiguro K, Iwai $\mathrm{T}$ (2020) Sentinel lymph node biopsy with preoperative CT lymphography and intraoperative indocyanine green fluorescence imaging for N0 early tongue cancer: A long-term follow-up study. J of Cranio-Maxillo Fac Surg 48(3): 217-222.

101. Stoeckli SJ (2007) Sentinel node biopsy for oral and oropharyngeal squamous cell carcinoma of the head and neck. Laryngoscope 117: 1539-1551.

102. Cheng PT, Hao SP, Lin YH, Yeh AR (2000) Objective comparison of shoulder dysfunction after three neck dissection techniques. Ann Otol Rhinol Laryngol 109(8): 761-766.

103. Van Wilgen CP, Dijkstra PU, Van Der Laan BF, Plukker JT (2004) Shoulder and neck morbidity in quality of life after surgery for head and neck cancer. Head Neck 26: 839-844.

104. Schiefke F, Akdemir M, Weber A, Akdemir D (2009) Function, postoperative morbidity, and quality of life after cervical sentinel node biopsy and after selective neck dissection. Head Neck 31: 503512.

105. Govers TM, Takes RP, Baris KM (2013) Management of the N0 neck in early stage oral squamous cell cancer: a modeling study of the costeffectiveness. Oral Oncol 49(8): 771-777.

106. Flach GB (2016) Patients perspective on the impact of sentinel node biopsy in oral cancer treatment. Oral Surg Oral Med Oral Pathol Oral Radiol: 122(3): 279-286.

107. Crile GW (1906) Excision of the cancer of the head and neck: with special reference to the plan of dissection based on one hundred and thirty two operations. JAMA 47: 1780-1786.

108. Shah JP, Candela FC, Poddar AK (1990) The patterns of cervical lymph node metastases from squamous carcinoma of the oral cavity. Cancer 66(1): 109-113.

109. Weiss MH, Harrison LB, Isaacs RS (1994) Use of decision analysis in planning a management strategy for the stage N0 neck. Arch Otolaryngol Head Neck Surg 120(7): 699-702.

110. Vandenbrouck C, Sancho GH, Chassagne D (1980) Elective versus therapeutic radical neck dissection in epidermoid carcinoma of the oral cavity: results of a randomized clinical trial. Cancer 46(2): 386390.

111. Barkley HT, Fletcher GH, Jesse RH (1972) Management of cervical lymph node metastases in squamous cell carcinoma of the tonsillar fossa, base of tongue, supraglottic larynx, and hypopharynx. Am J Surg 124(4): 462-467.

112. Bocca E, Pignataro O, Oldini C (1984) Functional neck dissection: an evaluation and review of 843 cases. Laryngoscope 94(7): 942-945. 
113. Lee DJ, Koch WM, Yoo G (1997) Impact of chromosome 14q loss on survival in primary head and neck squamous cell carcinoma. Clin Cancer Res 3(4): 501-505.

114. Levendag P, Vikram B (1987) The problem of neck relapse in early stage supraglottic cancer-results of different treatment modalities for the clinically negative neck. Int J Radiat Oncol Biol Phys; 13(11): 1621-1624

115. Mendenhall WM, Million RR, Cassisi NJ (1980) Elective neck irradiation in squamous-cell carcinoma of the head and neck. Head Neck Surg 3(1): 15-20.

116. Ogura JH, Biller HF, Wette R (1971) Elective neck dissection for pharyngeal and laryngeal cancers. An evaluation. Ann Otol Rhinol Laryngol 80(5): 646-653.

117. Pitman KT (2000) Rationale for elective neck dissection. Am J Otolaryngol 21(1): 31-37.

118. Pillsbury HC, Clark M (1997) A rationale for therapy of the N0 neck. Laryngoscope 107(10): 294-315.

119. Ferlito A, Rinaldo A, Silver CE, Gourin CG, Shah JP ((2006) Elective and therapeutic selective neck dissection. Oral Oncology 42(1): 1425 .

120. Johnson JT, Barnes EL, Myers EN, Schramm VL (1981) The extracapsular spread of tumors in cervical node metastasis. Arch Otolaryngol 107(12): 725-729.

121. Ferlito A, Rinaldo A, Devaney KO, MacLennan K, Myers JN, et al (2002) Prognostic significance of microscopic and macroscopic extracapsular spread from metastatic tumor in the cervical lymph nodes. Oral Oncol 38(8): 747-751.

122. Hirabayashi H, Koshii K, Uno K (1991) Extracapsular spread of squamous cell carcinoma in neck lymph nodes: Prognostic factor of laryngeal cancer. Laryngoscope 101(5): 502-506.

123. Ghadjar P, Schreiber H, Grater R (2010) Quantitative analysis of extracapsular extension of metstatic lymph nodes and its significance in radiotherapy planning in head and neck squamous cell carcinoma. Int J Radiat Oncol Biol Phys 76(4): 1127-1132.

124. Myers JN, Greenberg JS (2001) Extracapsular Spread A Significant Predictor of Treatment Failure in Patients with Squamous Cell Carcinoma of the Tongue. Cancer 92(12): 3030-3036.

125. Kreppel M, Nazarli P (2016) Clinical and histopathological staging in oral squamous cell carcinoma - Comparison of the prognostic significance. Oral Oncology 60: 68-73.

126. Koch WM, Ridge JA, Forastiere A, Manola J (2009) Comparison of clinical and pathological staging in head and neck squamous cell carcinoma: results from Intergroup Study ECOG 4393/RTOG 9614 Arch Otolaryngol Head Neck Surg 135(9): 851-858.

127. Mira E, Benazzo M, Rossi V, Zanoletti E (2002) Efficacy of selective lymph node dissection in clinically negative neck. Otolaryngol Head Neck Surg 127(4): 279-283.

128. Teichgraeber JF, Clairmont A (1984) The incidence of occult metastases for cancer of the oral tongue and floor of the mouth: treatment rationale. Head Neck 7(1): 15-21.

129. De Santo LW, Magrina C, O Fallon WM (1990) The second side of the neck in supraglottic cancer. Otolaryngol Head Neck Surg 102(4): 351-361.

130. Godden DR, Ribeiro NF, Hassanein K, Langton SG (2002) Recurrent neck disease in oral cancer. J Oral Maxillofac Surg 60(7): 748-753.

131. Mamelle G (2000) Selective neck dissection and sentinel node biopsy in head and neck squamous cell carcinomas. Recent Results Cancer Res 157: 193-200

132. Capote A, Escorial V, Munoz GMF, Rodriguez CFJ (2007) Elective neck dissection in early-stage oral squamous cell carcinoma-does it influence recurrence and survival? Head Neck 29(1): 3-11.

133. D Cruz AK, Vaish R, Kapre N, Mitali Dandekar, Sudeep Gupta, et al. (2015) Elective versus Therapeutic Neck Dissection in NodeNegative Oral Cancer. N Engl J Med 373: 521-529.

134. Kligerman J, Lima RA, Soares JR, Prado L, Dias FL, et al. (1994) Supraomohyoid neck dissection in the treatment of T1/T2 squamous cell carcinoma of oral cavity. Am J Surg 168: 391-394.

135. Keski Säntti H, Kontio R, Leivo I, Törnwall J, Mätzke S, et al. (2008) Sentinel lymph node biopsy as an alternative to wait and see policy in patients with small T1 oral cavity squamous cell carcinoma. Acta Otolaryngol 128(1): 98-102.

136. Keski Säntti H, Kontio R, Törnwall J, Leivo I, Mätzke S, et al. (2008) Sentinel lymph node biopsy or elective neck dissection for patients with oral squamous cell carcinoma? Eur Arch Otorhinolaryngol 265(Suppl 1): S13-S17.

137. Thiele OC, Seeberger R, Flechtenmacher C, Hofele C, Freier K (2012) The role of elective supraomohyoidal neck dissection in the treatment of early, node-negative oral squamous cell carcinoma (OSCC): A retrospective analysis of 122 cases. J of Cranio-MaxilloFacial Surg 40(1): 67-70.

138. Dillon JK, Villing A, Jones S, Futran N, Brockhoff H, et al. (2017) What Is the Role of Elective Neck Dissection in the Treatment of Patients With Buccal Squamous Cell Carcinoma and Clinically Negative Neck Findings? J Oral Maxillofac Surg 75(3): 603-608.

139. Oha LJ, Phanc SW, Kimc TH, Low TH, Gupta R, et al. (2020) Elective neck dissection versus observation for early-stage oral squamous cell carcinoma: Systematic review and meta-analysis. Oral Oncology 105: 104661 .

140. Ding Z, Xiao T, Huang J, Yuan Y, Ye Q et al. (2019) Elective Neck Dissection Versus Observation in Squamous Cell Carcinoma of Oral Cavity With Clinically N0 Neck: A Systematic Review and MetaAnalysis of Prospective Studies. J Oral Maxillofac Surg 77(1): 184194.

141. Fasunla AJ, Greene BH, Timmesfeld N, Wiegand S, Werner JA, et al. (2011) A meta-analysis of the randomized controlled trials on elective neck dissection versus therapeutic neck dissection in oral cavity cancers with clinically node-negative neck. Oral Oncology 47(5): 320-324.

142. Jerjes W, Upile T, Petrie A, Riskalla A, Hamdoon Z, et al. (2010) Clinicopathological parameters, recurrence, locoregional and distant metastasis in 115 T1-T2 oral squamous cell carcinoma patients. Head Neck Oncol 2: 9.

143. Montes DM, Carlson ER, Fernandes R, Ghali GE, Lubek, J, et al. (2011) Oral maxillary squamous cells carcinoma: an indication for neck dissection in the clinically negative neck. Head Neck 33(11): 15811585.

144. Feng Z, Li JN, Li CZ, Guo CB (2013) Elective neck dissection versus observation for $\mathrm{cN} 0$ neck of squamous cell carcinoma primarily located in the maxillary gingiva and alveolar ridge: a retrospective study of 129 cases. Oral Surg Oral Med Oral Pathol Oral Radiol 11695): 556-561.

145. Montes DM, Schmidt BL (2008) Oral maxillary squamous cell carcinoma: management of the clinically negative neck. J Oral Maxillofac Surg 66(4): 762-766. 


\section{Global Journal of Otolaryngology}

146. Poeschl PW, Seemann R, Czembirek C, Russmueller G, Sulzbacher I, et al. (2012) Impact of elective neck dissection on regional recurrence and survival in cN0staged oral maxillary squamous cell carcinoma. Oral Oncology 48(2): 173-178.

147. Joosten MH, De Bree R, Van Cann EM (2017) Management of the clinically node negative neck in squamous cell carcinoma of the maxilla. Oral Onc 66: 87-92.

148. Gavilán C, Gavilán J (1989) Five-year results of functional neck dissection for cancer of the larynx. Arch Otolaryngol Head Neck Surg 115(10): 1193-1196.

149. Kowalski LP (2002) Results of salvage treatment of the neck in patients with oral cancer. Arch Otolaryngol Head Neck Surg 128(1): 58-62.

150. Wong LY, Wei WI, Lam LK, Yuen AP (2003) Salvage of recurrent head and neck squamous cell carcinoma after primary curative surgery. Head Neck 25(11): 953-959.

151. Clark JR, Naranjo N, Franklin JH, de Almeida J, Gullane PJ (2006) Established prognostic variables in N0 oral carcinoma. Otolaryngol Head Neck Surg 135(5): 748-753.

152. Spiro RH, Huvos AG, Wong GY, Spiro JD, Gnecco CA, et al. (1986) Predictive value of tumor thickness in squamous carcinoma confined to the tongue and floor of the mouth. Am J Surg 152(4): 345-350.

153. Yuen AP, Lam KY, Chan AC, Wei WI, Lam LK, et al. (1999) Clinicopathological analysis of elective neck dissection for N0 neck of early oral tongue carcinoma. Am J Surg 177(1): 90-92.

154. Vishak S, Vinayak R (2014) Cervical node metastasis in T1 squamous cell carcinoma of oral tongue-pattern and the predictive factors. Indian J Surg Oncol 5(2): 104-108.

155. Kuan EC, St Clair JM, Badran KW, St John MA (2016) How Does Depth of Invasion Influence the Decision to Do a Neck Dissection in Clinically N0 Oral Cavity Cancer? Laryngoscope 126(3): 547-548.

156. Kurokawa H, Yamashita Y, Takeda S, Zhang M (2002) Risk factors for late cervical lymph node metastases in patients with stage I or II carcinoma of the tongue. Head Neck 24: 731-736.

157. Byers RM, El Naggar AK, Lee YY, Rao B (1998) Can we detect or predict the presence of occult nodal metastases in patients with squamous carcinoma of the oral tongue? Head Neck 20: 138-144.

158. Lim SC, Zhang S, Ishii G, Endoh Y, Kodama K (2004) Predictive markers for late cervical metastasis in stage I and II invasive squamous cell carcinoma of the oral tongue. Clin Cancer Res 1: 166-172.

159. Asakage T, Yokose T, Mukai K, Tsugane S, Tsubono Y, et al. (1998) Tumor thickness predicts cervical metastasis in patients with stage I/II carcinoma of the tongue. Cancer 82: 1443-1448.

160. Otsuru M, Aoki T (2016) Is an Elective Neck Dissection Necessary for All Cases of No Oral Squamous Cell Carcinoma?- Elective Neck Dissection may be Performed for Tongue Cancer with Tumor Thickness More than $4 \mathrm{~mm}$. Tokai J Exp Clin Med 41(3): 112-117.

161. Fukano H, Matsuura H, Hasegawa Y, Nakamura S (1997) Depth of invasion as a predictive factor for cervical lymph node metastasis in tongue carcinoma. Head Neck 19: 205-210.

162. Balasubramanian D, Ebrahimi A (2014) Tumour Thickness as predictor of nodal metastasis in oral cancer: comparison between tongue and floor of mouth subsites. Oral Oncol 50(12): 1165-1168.

163. Calearo CV, Teatini G (1983) Functional neck dissection. Anatomical grounds, surgical technique, clinical observations. Ann Otol Rhinol Laryngol 92: 215-222.

164. Lea J, Bachar G, Sawka AM, Lakra DC, Gilbert RW (2010) Metastases to level IIb in squamous cell carcinoma of the oral cavity: a systematic review and metaanalysis. Head Neck 32: 184-190.

165. Whitehurst J0, Droulias CA (1977) Surgical treatment of squamous cell carcinoma of the oral tongue: factors influencing survival. Arch Otolaryngol 103: 212-215.

166. Decroix Y, Ghossein NA (1981) Experience of the Curie Institute in treatment of cancer of the mobile tongue. II. Management of the neck nodes. Cancer 47: 503-508.

167. Hughes CJ, Gallo O, Spiro RH, Shah JP (1993) Management of occult neck metastases in oral cavity squamous carcinoma. Am J Surg 166: 380-383.

168. Franceschi D, Gupta R, Spiro RH, Shah JP (1993) Improved survival in the treatment of squamous carcinoma of the oral tongue. Am J Surg 166: $360-365$

169. Haddadin KJ, Soutar DS, Oliver RJ, Webster MH, Robertson AG (1999) Improved survival for patients with clinically T1/T2, N0 tongue tumors undergoing a prophylactic neck dissection. Head Neck 21: 517-525.

170. Bartella AK (2016) "IIb or not IIb": The necessity of dissection in patients with oral squamous cell carcinoma. Journal of CranioMaxillo-Facial Surgery 44: 1733-1736.

171. Maher NG, Hoffman GR (2014) Elective neck dissection for primary oral cavity squamous cell carcinoma involving the tongue should include sublevel IIb. J Oral Maxillofac Surg 72: 2333-2343.

172. Erisen L, Basel B (2004) Shoulder Function after Accessory-nerve sparing Neck Dissections. Head Neck 26: 967-971.

173. De Cicco C, Trifirò G, Calabrese L, Bruschini R, Ferrari ME (2006) Lymphatic mapping to tailor selective lymphadenectomy in $\mathrm{cNO}$ tongue carcinoma: beyond the sentinel node concept. Eur J Nucl Med Mol Imaging 33: 900-905.

174. Byers RM, Weber RS, Andrews T, McGill D, Kare R (1997) Frequency and therapeutic implications of "skip metastases" in the neck from squamous carcinoma of the oral tongue. Head Neck 19: 14-19.

175. De Zinis LO, Bolzoni A, Piazza C, Nicolai P (2006) Prevalence and localization of nodal metastases in squamous cell carcinoma of the oral cavity: role and extension of neck dissection. Eur Arch Otorhinolaryngol 263: 1131-1135.

176. Ferlito A, Silver C (2009) Elective management of the neck in oral cavity squamous carcinoma: current concepts supported by prospective studies. Br J of Oral Maxillofac Surg 47: 5-9.

177. Davidson J, Biem J, Detsky A (1995) The clinically negative neck in patients with early oral cavity carcinoma: a decision analysis approach to management. J Otolaryngol 24: 323-329.

178. Li XM, Wei WI, Guo XF, Yuen PW, Lam LK (1996) Cervical lymph node metastatic patterns of squamous carcinomas of the upper aerodigestive tract. J Laryngol Otol 110: 937-941.

179. Shah JP, Andersen PE (1995) Evolving role of modifications in neck dissection for oral squamous carcinoma. Br J Oral Maxillofac Surg 33: 3-8.

180. Woolgar JA (1999) Histological distribution of cervical lymph node metastases from intraoral/ oropharyngeal squamous cell carcinomas. Br J Oral Maxillofac Surg 37: 205-209.

181. Byers RM, Weber RS, Andrews T, McGill D, Kare R (1997) Frequency and therapeutic implications of "skip metastases" in the neck from squamous carcinoma of the oral tongue. Head Neck 19: 14-19.

182. Ahmed MU, Khawar A, Ahmed J, Ajmal M, Bangash WK (2007) Occult metastasis in carcinoma of oral cavity. J Coll Physicians Surg Pak 17(6): 313-315 


\section{Global Journal of Otolaryngology}

183. Chuanzhen L (2015) Analysis of Risk Factors of Level ? Metastasis in Cervical Lymph Nodes of Patients with Primary Tongue Squamous Cell. Chinese J of Stomatology 50(06): 366-368.

184. Balasubramanian D (2012) Isolated Skip Nodal Metastasis Is Rare in T1 and T2 Oral Tongue Squamous Cell Carcinoma. OtolaryngologyHead and Neck Surgery 147(2): 275-277.

185. Langroudi MM, Amali A (2016) Occult level IV metastases in clinically node negative patients with oral tongue squamous cell carcinoma. The J of Laryngology \& Otology 130: 474-477.

186. Khafif A, Lopez Garza JR, Medina JE (2001) Is dissection of level IV necessary in patients with T1-T3 N0 tongue cancer? Laryngoscope 111: 1088-1090.

187. Bajwa MS (2011) Neck Recurrence After Level I-IV or I-III Selective Neck Dissection in the Management of the Clinically N0 Neck in patients with Oral Squamous Cell Carcinoma. Head Neck 33: 403406.

188. Dias FL, Lima RA (2006) Relevance of Skip Metastases for Squamous Cell Carcinoma of the Oral Tongue and the Floor of the Mouth Otolaryngology-Head and Neck Surgery 134: 460-465.

189. Dogan E, Cetinayak HO, Sarioglu S (2014) Patterns of cervical lymph node metastases in oral tongue squamous cell carcinoma: implications for elective and therapeutic neck dissection. J Laryngol Otol 128(3): 268-273.

190. Feng Z, Li JN, Niu LX, Guo CB (2014) Supraomohyoid neck dissection in the management of oral squamous cell carcinoma: special consideration for skip metastases at level IV or V. J Oral Maxillofac Surg 72(6): 1203-1211.

191. Mizen KD, Mitchell DA (2005) Anatomical variability of omohyoid and its relevance in oropharyngeal cancer. Br J of Oral Maxillo Surg 43(4): 285-288

192. Werner JA, Dünne AA, Myers JN (2002) Functional anatomy of the lymphatic drainage system of the upper aerodigestive tract and its role in metastasis of squamous cell carcinoma. Head Neck 25: 322 324

193. Freire AR, Lima ER, Almeida OR, Kowalski LR (2003) Computed tomography and lymphoscintigraphy to identify lymph node metastases and lymphatic drainage pathways in oral and oropharyngeal squamous cell carcinomas. Eur Arch Otorhinolaryngol 260: $148-152$

194. Robbins KT, Clayman G, Levine PA, Medina J, Sessions R, et al. (2002) Neck dissection classification update: revisions proposed by the American Head and Neck Society and the American Academy of Otolaryngology-Head and Neck Surgery. Arch Otolaryngol Head Neck Surg 128(7): 751-758.

195. Lindberg R (1972) Distribution of cervical lymph node metastases from squamous cell carcinoma of the upper respiratory and digestive tracts. Cancer 29(6): 1446-1459.

196. Chow JM, Levin BC, Krivit JS, Applebaum EL (1989) Radiotherapy or surgery for subclinical cervical node metastases. Arch Otolaryngol Head Neck Surg 115: 981-984.

197. Pillsbury 3rd HC, Clark M (1997) A rationale for therapy of the N0 neck. Laryngoscope 107: 1294.

198. Wei WI, Ferlito A, Rinaldo A (2006) Management of the N0 neck-reference or preference. Oral Oncol 42(2): 115-122.

199. Robertson AG, Soutar DS, Paul J, Webster M, Leonard AG, et al. (1998) Early closure of a randomized trial: surgery and postoperative radiotherapy versus radiotherapy in the management of intra-oral tumours. Clin Oncol (R Coll Radiol) 10: 155-160.

200. Wendt CD, Peters LJ, Delclos L, Ang KK, Morrison WH, et al. (1990)
Primary radiotherapy in the treatment of stage I and II oral tongue cancers: importance of the proportion of therapy delivered with interstitial therapy. Int J Radiat Oncol Biol Phys 18: 1287-1292.

201. Ayad T, Gelinas M (2005) Retromolar Trigone Carcinoma Treated by Primary Radiation Therapy An Alternative to the Primary Surgical Approach. Arch Otolaryngol Head Neck Surg 131: 576-582.

202. Gonzalez Moles MA, Esteban F, Rodriguez Archilla A, Ruiz Avila I, et al (2002) Importance of tumour thickness measurement in prognosis of tongue cancer. Oral Oncol 38(4): 394-397.

203. Wendt CD, Peters LJ, Delclos L, Ang KK, Morrison WH, et al. (1990) Primary radiotherapy in the treatment of stage I and II oral tongue cancers: importance of the proportion of therapy delivered with interstitial therapy. Int J Radiat Oncol Biol Phys 18: 1287-1292.

204. Mazeron JJ, Crook JM, Marinello G, Walop W, Pierquin B (1990) Prognostic factors of local outcome for T1, T2 carcinomas of oral tongue treated by iridium 192 implantation. Int J Radiat Oncol Biol Phys 19(2): 281-285.

205. Beeken L, Calman F (1994) A return to "normal eating" after curative treatment for oral cancer. What are the longterm prospects? Eur J Cancer B Oral Oncol 30B: 387-392.

206. Bundgaard T, Tandrup 0, Elbrond 0 (1993) A functional evaluation of patients treated for oral cancer. A prospective study. Int J Oral Maxillofac Surg 22: 28-34

207. Finlay PM, Dawson F, Robertson AG, Soutar DS (1992) An evaluation of functional outcome after surgery and radiotherapy for intraoral cancer. Br J Oral Maxillofac Surg 30: 14-17.

208. Krouse JH, Krouse HJ, Fabian R (1989) Adaptation to surgery for head and neck cancer. Laryngoscope 99: 789-794.

209. Pauloski BR, Rademaker AW, Logemann JA, Colangelo LA (1998) Speech and swallowing in irradiated and nonirradiated postsurgical oral cancer patients. Otolaryngol Head Neck Surg 118: 616-624.

210. Rogers SN, Lowe D, Brown JS, Vaughan ED (1999) The University of Washington head and neck cancer measure as a predictor of outcome following primary surgery for oral cancer. Head Neck 21: 394-401.

211. M Veness, S Richards (2003) Role of modern radiotherapy in treating skin cancer. Australas J Dermatol 44(3): 159-168.

212. Rowell N (2007) Radiotherapy in the management of orofacial cancer. In: Ward Booth P, Schendel SA, Hausamen JE (Eds.), (2 ${ }^{\text {nd }}$ edn), Maxillofacial surgery 1: 331-351.

213. Taylor RJ, Chepeha JC, Teknos TN (2002) Development and validation of the neck dissection impairment index: a quality of life measure. Arch Otolaryngol Head Neck Surg 128(1): 44-49.

214. Denham JW, Peters LJ, Johansen J (1999) Do acute mucosal reactions lead to consequential late reactions in patients with head and neck cancer? Radiother Oncol 52(2): 157-164.

215. Spaulding CA, Korb LJ, Constable WC, Cantrell RW, Levine PA (1991) The influence of extent of neck treatment upon control of cervical lymphadenopathy in cancers of the oral tongue. Int J Radiat Oncol Biol Phys 21: 577-581.

216. Jang WI, Wu HG, Park CI (2008) Treatment of Patients with Clinically Lymph Node-negative Squamous Cell Carcinoma of the Oral Cavity. Jpn J Clin Oncol 38 (6): 395-401.

217. Corvò R, Foppiano F, Bacigalupo A, Berretta L, Benasso M, et al (2004) Contralateral parotid-sparing radiotherapy in patients with unilateral squamous cell carcinoma of the head and neck: technical methodology and preliminary results. Tumori 90: 66-72.

218. Maesschalck T, Dulguerov N (2016) Comparison of the incidence of osteoradionecrosis with conventional radiotherapy and intensity- 


\section{Global Journal of Otolaryngology}

modulated radiotherapy. Head Neck 38(11): 1695-1702.

219. Duarte VM, Liu YF, Rafizadeh S, Tajima T (2014) Comparison of Dental Health of Patients with Head and Neck Cancer Receiving IMRT vs Conventional Radiation. Otolaryngology- Head and Neck Surgery 150(1): 81-86.

220. Vergeer MR, Doornaert PAH (2009) Intensity-Modulated Radiotherapy Reduces Radiation-Induced Morbidity and Improves Health-Related Quality of Life: Results of a Nonrandomized Prospective Study Using a Standardized Follow-Up Program. Int J Rad Onc Bio Physics 74(1): 1-8.

221. Gomez DR, Zhung JE (2009) Intensity-Modulated Radiotherapy in Postoperative Treatment of Oral Cavity Cancers. Int J Rad Onc Bio Physics 73(4): 1096-1103.

222. Graff P (2007) Impact of Intensity-Modulated Radiotherapy on Health-Related Quality of Life for Head and Neck Cancer Patients: Matched-Pair Comparison with Conventional Radiotherapy. Int J Rad Onc Bio Physics 67(5): 1309-1317.

223. Ishigami T, Uzawa K (2007) Genes and molecular pathways related to radioresistance of oral squamous cell carcinoma cells. Int J Cancer 120: 2262-2270.

224. Kalen AL, Sarsour EH, Venkataraman S (2006) Mn-superoxide dismutase overexpression enhances G2 accumulation and radioresistance in human oral squamous carcinoma cells. Antioxid Redox Signal 8: 1273-1281.

225. Bernier J, Domenge C, Ozsahin M, Matuszewska K, Lefebvre JL (2004) European Organization for Research and Treatment of Cancer Trial 22931. Postoperative irradiation with or without concomitant chemotherapy for locally advanced head and neck cancer. N Engl J Med 350: 1945-1952.

226. Cooper JS, Pajak TF, Forastiere AA, Jacobs J, Campbell BH (2004) Radiation Therapy Oncology Group 9501/Intergroup. Postoperative concurrent radiotherapy and chemotherapy for high-risk squamouscell carcinoma of the head and neck. N Engl J Med 350: 1937-1944.

227. Licitra L, Grandi C (2003) Primary Chemotherapy in Resectable Oral Cavity Squamous Cell Cancer: A Randomized Controlled Trial. J of Clin Onc 21(2): 327-333.

228. Pignon JP (2009) Meta-analysis of chemotherapy in head and neck cancer (MACH-NC): An update of 93 randomized trials and 17,346 patients. Radiotherapy and Oncology 9(1): 4-14.

229. Kies MS, Dowin H (2012) Phase II trial of induction chemotherapy followed by surgery for squamous cell carcinoma of the oral tongue in young adults. Head Neck 34: 1255-1262.

230. Adelstein DJ, Sharan VM (1992) Concurrent radiation therapy, 5-fluorouracil, and cisplatin for stage II, III, IV, node-negative, squamous cell head and neck cancer. Results and surgical implications. Cancer 70(11): 2685-2690.

231. Kirita T, Ohgi K, Shimooka H, Yamanaka Y (1999) Preoperative concurrent chemoradiotherapy plus radical surgery for advanced squamous cell carcinoma of the oral cavity: an analysis of long-term results. Oral Oncol 35(6): 597-606.

232. Eckardt A, Wildfang I, Karstens JH (1999) Simultaneous radiochemotherapy with taxol/carboplatin in advanced operable headneck tumors. Preliminary results. Strahlenther Onkol 175: 311313.

233. Slotman GJ, Doolittle CH, Glicksman AS (1992) Preoperative combined chemotherapy and radiation therapy plus radical surgery in advanced head and neck cancer. Five-year results with impressive complete response rates and high survival. Cancer 69(11): 27362743 .
234. Salama JK, Seiwert TY, Vokes EE (2007) Chemoradiotherapy for locally advanced head and neck cancer. J Clin Oncol 25: 4118-4126.

235. Pignon JP, Bourhis J, Domenge C, Designe L (2000) Chemotherapy added to locoregional treatment for head and neck squamous cell carcinoma: three meta-analyses of updated individual data. MACHNC Collaborative Group. Meta-analysis of chemotherapy on head and neck cancer. Lancet 355(9208): 949-955.

236. Colnot DR, Neiuwenhuis EJ (2001) Ultrasound-guided aspiration of sentinel nodes for improved staging of head and neck cancer patients - initial experience. Radiology 218: 289-293.

237. Lydiatt DD, Robbins KT, Byers RM, Wolf PF (1993) Treatment of stage I and II oral tongue cancer. Head Neck 15: 308-312.

238. Yuen AP, Wei WI, Wong YM, Tang KC (1997) Elective neck dissection versus observation in the treatment of early oral tongue carcinoma. Head Neck 19: 583-588.

239. D'Cruz AK, Siddachari RC, Walvekar RR (2009) Elective neck dissection for the management of the N0 neck in early cancer of the oral tongue: need for a randomized controlled trial. Head Neck 31(5): 618-624.

240. Tsang RKY, Chung JCK (2011) Efficacy of salvage neck dissection for isolated nodal recurrences in early carcinoma of the oral tongue with watchful waiting management of initial N0 neck. Head Neck 33: $1482-1485$

241. Andersen PE, Cambronero E, Shaha AR, Shah JP (1996) The extent of neck disease after regional failure during observation of the N0 neck. Am J Surg 172: 689-691.

242. Flach GB, Tenhagen M, de Bree R (2013) Outcome of patients with early stage oral cancer managed by an observation strategy towards the N0 neck using ultrasound guided fine needle aspiration cytology: no survival difference as compared to elective neck dissection. Oral Oncol 49(2): 157-164

243. NCCN Clinical Practice Guidelines in Oncology: Head and Neck Cancers. Version 1.2015. Available at NCCN.org

244. Ho CM, Lam KH, Wei WI, Lau SK, Lam LK (1992) Occult lymph node metastasis in small oral tongue cancers. Head Neck 14: 359-363.

245. Mohanti BK, Nachiappan P, Pandey RM, Sharma A, Bahadur S, et al. (2007) Analysis of 2167 head and neck cancer patients' management, treatment compliance and outcomes from a regional cancer centre, Delhi, India. J Laryngol Otol 121: 49-56.

246. Keski Säntti H, Atula T, Törnwall J, Koivunen P, Mäkitie A (2006) Elective neck treatment versus observation in patients with T1/T2 N0 squamous cell carcinoma of oral tongue. Oral Oncol 42(1): 96101.

247. Lim YC, Lee JS, Koo BS, Kim SH (2006) Treatment of contralateral N0 neck in early squamous cell carcinoma of the oral tongue: elective neck dissection versus observation. Laryngoscope 116(3): 461-465.

248. Dias FL, Kligerman J (2001) Elective neck dissection versus observation in stage I squamous cell carcinomas of the tongue and floor of the mouth. Otolaryngol Head Neck Surg 125(1): 23-29.

249. Fakih AR1, Rao RS, Borges AM, Patel AR (1989) Elective versus therapeutic neck dissection in early carcinoma of the oral tongue. Am J Surg 158(4): 309-313.

250. Chung $\mathrm{CH}$, Parker JS, Karaca G (2004) Molecular classification of head and neck squamous cell carcinomas using patterns of gene expression. Cancer Cell 5: 489-500.

251. Warner GC, Reis PP, Jurisica I (2004) Molecular classification of oral cancer by cDNA microarrays identifies overexpressed genes correlated with nodal metastasis. Int J Cancer 110: 857-868. 
252. Bova RJ, Quinn DI, Nankervis JS (1999) Cyclin D1 and p16INK4A expression predict reduced survival in carcinoma of the anterior tongue. Clin Cancer Res 5(10): 2810-2819.

253. Nakayama S, Sasaki A, Mese H (1998) Establishment of high and low metastasis cell lines derived from a human tongue squamous cell carcinoma. Invasion Metastasis 18(5-6): 219-228.

254. Tanaka N, Odajima T, Ogi K (2003) Expression of E-cadherin, alphacatenin, and beta-catenin in the process of lymph node metastasis in oral squamous cell carcinoma. Br J Cancer 89(3): 557-563.

255. Juarez J, Clayman G, Nakajima M (1993) Role and regulation of expression of 92-kDa type-IV collagenase (MMP-9) in 2 invasive squamous-cell-carcinoma cell lines of the oral cavity. Int J Cancer 55(1): 10-18.

256. Clayman G, Wang SW, Nicolson GL, et al. (1993) Regulation of urokinase-type plasminogen activator expression in squamous-cell carcinoma of the oral cavity. Int J Cancer 54(1): 73-80.
257. Stringer BK, Cooper AG, Shepard SB (2001) Overexpression of the G-protein inwardly rectifying potassium channel 1 (GIRK1) in primary breast carcinomas correlates with axillary lymph node metastasis. Cancer Res 61(2): 582-588.

258. Ohta T, Numata M, Yagishita $H$ (1996) Expression of $16 \mathrm{kDa}$ proteolipid of vacuolar-type $\mathrm{H}(+)$-ATPase in human pancreatic cancer. Br J Cancer 73(12): 1511-1517.

259. Van Hooff SR, Leusink FK, Roepman P (2012) Validation of a gene expression signature for assessment of lymph node metastasis in oral squamous cell carcinoma. J Clin Oncol 30: 4104-4110.

260. O’Donnell RK, Kupferman M, Wei SJ (2005) Gene expression signature predicts lymphatic metastasis in squamous cell carcinoma of the oral cavity. Oncogene 24: 1244-1251.

261. Lydiatt WM, Patel SG, O’Sullivan B (2017) Head and Neck Cancers Major Changes in the American Joint Committee on Cancer Eighth Edition Cancer Staging Manual. A Cancer Journal for Clinicians 67(2): 122-137.

\section{Your next submission with Juniper Publishers will reach you the below assets}

- Quality Editorial service

- Swift Peer Review

- Reprints availability

- E-prints Service

- Manuscript Podcast for convenient understanding

- Global attainment for your research

- Manuscript accessibility in different formats

( Pdf, E-pub, Full Text, Audio)

- Unceasing customer service

Track the below URL for one-step submission https://juniperpublishers.com/online-submission.php 